\title{
Combustion Rate of Solid Carbon in the Axisymmetric Stagnation Flowfield Established over a Sphere and/or a Flat Plate
}

\author{
Atsushi Makino, ${ }^{1}$ Masahiro Hojo, ${ }^{1}$ and Masahito Shintomi ${ }^{2}$ \\ ${ }^{1}$ Aerospace Research and Development Directorate, Japan Aerospace Exploration Agency, 7-44-1 Jindaiji-Higashi, \\ Chofu, Tokyo 182-8522, Japan \\ ${ }^{2}$ Department of Mechanical Engineering, Numadu National College of Technology, 3600 O-oka, Numadu 410-8501, Japan
}

Correspondence should be addressed to Atsushi Makino; amakino@chofu.jaxa.jp

Received 29 November 2012; Revised 4 February 2013; Accepted 4 February 2013

Academic Editor: Yiguang Ju

Copyright (C) 2013 Atsushi Makino et al. This is an open access article distributed under the Creative Commons Attribution License, which permits unrestricted use, distribution, and reproduction in any medium, provided the original work is properly cited.

\begin{abstract}
Carbon combustion in the forward stagnation flowfield has been examined through experimental comparisons, by conducting aerothermochemical analyses, with the surface $\mathrm{C}-\mathrm{O}_{2}$ and $\mathrm{C}-\mathrm{CO}_{2}$ reactions and the gas-phase $\mathrm{CO}-\mathrm{O}_{2}$ reaction taken into account. By virtue of the generalized species-enthalpy coupling functions, close coupling of those reactions has been elucidated. Explicit combustion-rate expressions by use of the transfer number in terms of the natural logarithmic term, just like that for droplet combustion, have further been obtained for the combustion response in the limiting situations. It has been confirmed that before the establishment of $\mathrm{CO}$ flame, the combustion rate can fairly be represented by the expression in the frozen mode, that after its establishment by the expression in the flame-attached or flame-detached modes, and that the critical condition derived by the asymptotics can fairly predict the surface temperature for its establishment. The formulation has further been extended to include the surface $\mathrm{C}-\mathrm{H}_{2} \mathrm{O}$ and gas-phase $\mathrm{H}_{2}-\mathrm{O}_{2}$ reactions additionally, so as to evaluate the combustion rate in humid airflow. Since those expressions are explicit and have fair accuracy, they are anticipated to make various contributions not only for qualitative/quantitative studies, but also for various aerospace applications, including propulsion with high-energy-density fuels.
\end{abstract}

\section{Introduction}

Carbon combustion has been a research subject, indispensable for practical utilization of coal/char combustion, aerospace applications with carbon-carbon composites (C/Ccomposites), ablative carbon heat shields, and/or propulsion with using high-energy-density fuels. Because of this practical importance, extensive research has been conducted not only experimentally but also theoretically/numerically, and several comprehensive reviews [1-12] summarize accomplishments in this field. Nevertheless, because of complexities involved, there still remain several problems indispensable for understanding the basic nature of the combustion. Some of them also command fundamental interest, because of simultaneous existence of surface and gas-phase reactions, interacting with each other.
Generally speaking, the carbon combustion consists of the following processes:

(1) diffusion of oxidizing species to the solid surface,

(2) adsorption of molecules onto active sites on the surface,

(3) formation of products from adsorbed molecules on the surface,

(4) desorption of solid oxides into the gas phase,

(5) migration of gaseous products through the boundary layer into the freestream.

The slowest of them determines the combustion rate because these steps occur in series. Note that steps (2) and (4) are extremely fast, in general. 
When the surface temperature is low, step (3) is known to be much slower than steps (1) or (5), so that the combustion rate, defined as mass being transferred in unit area and time, is determined solely by chemical kinetics. Since the process in this regime is kinetically controlled, the combustion rate only depends on the surface temperature, exponentially. To the contrary, the process of diffusion that proceeds in the boundary layer is irrelevant, so that the combustion rate is independent of its thickness; thereby, concentrations of oxidizing species at the reacting surface are not too different from those in the freestream. Furthermore, since solid carbon is more or less porous, in general, combustion proceeds throughout the sample specimen.

When the surface temperature is high, step (3) is known to be much faster than steps (1) and (5), so that the combustion rate is controlled by the diffusion rate of oxidizing species (say, oxygen) to the solid surface, where their concentrations are negligibly small. In this diffusionally controlled regime, therefore, the combustion rate, exhibiting surface regression, strongly depends on the boundary layer thickness, while its dependence on the surface temperature is weak $\left(\propto T^{0.5 \sim 1.0}\right)$.

Since oxygen transfer to the carbon surface can occur via $\mathrm{O}_{2}, \mathrm{CO}_{2}$, and $\mathrm{H}_{2} \mathrm{O}$, the major surface reactions can be

$$
\begin{gathered}
\mathrm{C}+\mathrm{O}_{2} \longrightarrow \mathrm{CO}_{2} \\
2 \mathrm{C}+\mathrm{O}_{2} \longrightarrow 2 \mathrm{CO} \\
\mathrm{C}+\mathrm{CO}_{2} \longrightarrow 2 \mathrm{CO} \\
\mathrm{C}+\mathrm{H}_{2} \mathrm{O} \longrightarrow \mathrm{CO}+\mathrm{H}_{2}
\end{gathered}
$$

At higher temperatures, say, higher than $1000 \mathrm{~K}$, it is generally recognized that $\mathrm{CO}$ formation is the preferred route and that the relative contribution of (R1) can be negligible [13]. Thus, in the following, reaction (R2) will be referred to as the $\mathrm{C}-\mathrm{O}_{2}$ reaction.

Comparing (R2) and (R3), as alternate routes of $\mathrm{CO}$ production, the $\mathrm{C}-\mathrm{O}_{2}$ reaction is the preferred route for $\mathrm{CO}$ production at low temperatures, in simultaneous presence of $\mathrm{O}_{2}$ and $\mathrm{CO}_{2}$. It can be initiated around $600 \mathrm{~K}$ and saturated around $1600 \mathrm{~K}$, proceeding infinitely fast, eventually, relative to diffusion. The $\mathrm{C}-\mathrm{CO}_{2}$ reaction of $(\mathrm{R} 3)$ is the high temperature route, initiating around $1600 \mathrm{~K}$ and becoming saturated around $2500 \mathrm{~K}$. It is of particular significance because $\mathrm{CO}_{2}$ in (R3) can even be the product of the gas-phase, watercatalyzed, $\mathrm{CO}$ oxidation

$$
2 \mathrm{CO}+\mathrm{O}_{2} \longrightarrow 2 \mathrm{CO}_{2}
$$

referred to as the $\mathrm{CO}-\mathrm{O}_{2}$ reaction. Thus, the $\mathrm{C}-\mathrm{CO}_{2}$ and $\mathrm{CO}-$ $\mathrm{O}_{2}$ reactions can form a loop.

Similarly, the $\mathrm{C}-\mathrm{H}_{2} \mathrm{O}$ reaction ( $\left.\mathrm{R} 4\right)$, generating $\mathrm{CO}$ and $\mathrm{H}_{2}$, is also important when the combustion environment consists of an appreciable amount of water. This reaction is also of significance because $\mathrm{H}_{2} \mathrm{O}$ is the product of the $\mathrm{H}_{2}$ oxidation

$$
2 \mathrm{H}_{2}+\mathrm{O}_{2} \longrightarrow 2 \mathrm{H}_{2} \mathrm{O}
$$

referred to as the $\mathrm{H}_{2}-\mathrm{O}_{2}$ reaction, which then constitutes a loop with the $\mathrm{C}-\mathrm{H}_{2} \mathrm{O}$ reaction.
The present study is intended to shed more light on the carbon combustion, with putting a focus on its combustion rate under an interaction of the surface and gas-phase reactions. It is, therefore, not intended as a collection of engineering data or an exhaustive review of all the pertinent work published. Rather, it has an intention to represent the carbon combustion by use of some of the basic characteristics of the chemically reacting boundary layers, under recognition that flow configurations are indispensable for proper evaluation of the combustion rate, especially under the situation in which the gas-phase reaction can intimately affect overall combustion response through its coupling to the surface reactions.

Among various flow configurations, it has been reported that the stagnation-flow configuration has various advantages, because it provides a well-defined, one-dimensional flow, characterized by a single parameter [14], called as the stagnation velocity gradient. It has even been said that mathematical analyses, experimental data acquisition, and physical interpretations have been facilitated by its introduction. Since carbon combustion in the two-dimensional stagnation flow, established over a cylinder, has already been summarized somewhere in a set of review papers $[15,16]$, in which extensive comparisons have been conducted between experimental and theoretical/numerical results, here we confine ourselves to studying carbon combustion in the axisymmetric stagnation flow over a sphere or a flat plate, by comparing experimental data in the literature with theoretical/numerical results, newly obtained. From the practical point of view, we can even say that it simulates the situations of ablative carbon heat-shields and/or the strongly convective carbon burning in the forward stagnation region of a particle.

In the following, formulation of the governing equations is first presented in Section 2, based on theories on the chemically reacting boundary layer in the forward stagnation field. Chemical reactions considered are the surface $\mathrm{C}-\mathrm{O}_{2}$ and $\mathrm{C}-\mathrm{CO}_{2}$ reactions and the gas-phase $\mathrm{CO}-\mathrm{O}_{2}$ reaction. Generalized species-enthalpy coupling functions are then derived without assuming any limit or near-limit behaviors, which not only enable us to minimize the extent of numerical efforts needed for generalized treatment, but also provide useful insight into the conserved scalars in the carbon combustion. In Section 3, it is also shown that straightforward derivation of the combustion response can be allowed in the limiting situations, so that we have those for the frozen, flamedetached, and flame-attached modes.

In Section 4, a further analytical study is made about the ignition phenomenon in the gas phase, related to finiterate kinetics, by use of the asymptotic expansion method to obtain a critical condition. Appropriateness of this criterion is further examined by comparing surface temperatures at which the CO flame can appear. After having constructed the theory, evaluation of kinetic parameters of the global gas-phase reaction is conducted, for further experimental comparisons.

In Section 5, it is endeavored to obtain explicit combustion-rate expressions, even though they might be approximate, because they are anticipated to contribute much to the foundation of theoretical understanding of carbon 
combustion, offering mathematical simplifications, just like that in droplet combustion, and to the practical applications in the fields of aerospace and/or others. Further experimental comparisons are conducted by use of results reported in the literature.

After having examined appropriateness of the explicit expressions, carbon combustion in humid airflow is then examined in Section 6, relevant to basic research for erosive attacks of water vapor to $\mathrm{C} / \mathrm{C}$-composite in rocket nozzles, for example. Endeavor has been made for extending formulations for the system with three surface reactions and two global gas-phase reactions, in order to conduct experimental comparisons at high concentrations of the water vapor.

Concluding remarks are made in Section 7, with nomenclature tables and references cited.

\section{Formulation}

Among previous studies [17-21], it may be noted that Adomeit's group has made a great contribution by clarifying water-catalyzed $\mathrm{CO}-\mathrm{O}_{2}$ reaction [18], conducting experimental comparisons [19], and investigating ignition/extinction behavior of the CO flame [20]. Here, an extension of the worthwhile contributions is made along the following directions. First, simultaneous presence of the surface $\mathrm{C}-\mathrm{O}_{2}$ and $\mathrm{C}-\mathrm{CO}_{2}$ reactions and the gas-phase $\mathrm{CO}-\mathrm{O}_{2}$ reaction is included, so as to allow studies of surface reactions over an extended range of its temperatures, as well as to examine their coupling with the gas-phase reaction. Second, a set of generalized coupling functions [22] are conformed to the present flow configuration, in order to facilitate mathematical development and/or physical interpretation of the results. Third, an attempt is made to identify effects of thermophysical properties, as well as other kinetic and system parameters involved. Note here, however, that explanations cannot help but be similar to those in the previous work [15] because the formulation of the carbon combustion in the stagnation flowfield has been constructed in a generalized manner, regardless of the flow configuration, whether it is axisymmetric or twodimensional.

2.1. Model Definition. The present model simulates the isobaric carbon combustion of constant surface temperature $T_{\mathrm{s}}$ in the stagnation flow of temperature $T_{\infty}$, oxygen massfraction $Y_{\mathrm{O}, \infty}$, and carbon dioxide mass-fraction $Y_{\mathrm{P}, \infty}$, in a general manner [23]. The major reactions considered are the surface $\mathrm{C}-\mathrm{O}_{2}$ and $\mathrm{C}-\mathrm{CO}_{2}$ reactions and the gas-phase $\mathrm{CO}-\mathrm{O}_{2}$ reaction. The surface $\mathrm{C}+\mathrm{O}_{2} \longrightarrow \mathrm{CO}_{2}$ reaction is excluded [13] because our concern is the combustion at temperatures above $1000 \mathrm{~K}$. Crucial assumptions introduced are conventional, constant property assumptions with unity Lewis number, constant average molecular weight, constant value of the product of density $\rho$ and viscosity $\mu$, onestep overall irreversible gas-phase reaction, and first-order surface reactions. Surface characteristics, such as porosity and internal surface area, are grouped into the frequency factors for the surface reactions.
2.2. Governing Equations. The steady-state axisymmetric and/or two-dimensional boundary-layer flows with chemical reactions are governed as follows $[24,25]$.

Continuity:

$$
\frac{\partial\left(\rho u R^{j}\right)}{\partial x}+\frac{\partial\left(\rho v R^{j}\right)}{\partial y}=0
$$

Momentum:

$$
\rho u \frac{\partial u}{\partial x}+\rho v \frac{\partial u}{\partial y}-\frac{\partial}{\partial y}\left(\mu \frac{\partial u}{\partial y}\right)=\rho_{\infty} u_{\infty}\left(\frac{\partial u}{\partial x}\right)_{\infty} .
$$

Species:

$$
\begin{aligned}
& \rho u \frac{\partial Y_{i}}{\partial x}+\rho v \frac{\partial Y_{i}}{\partial y}-\frac{\partial}{\partial y}\left(\rho D \frac{\partial Y_{i}}{\partial y}\right)=-w_{i} \quad(i=\mathrm{F}, \mathrm{O}), \\
& \rho u \frac{\partial Y_{\mathrm{P}}}{\partial x}+\rho v \frac{\partial Y_{\mathrm{P}}}{\partial y}-\frac{\partial}{\partial y}\left(\rho D \frac{\partial Y_{\mathrm{P}}}{\partial y}\right)=w_{\mathrm{P}} \\
& \rho u \frac{\partial Y_{\mathrm{N}}}{\partial x}+\rho v \frac{\partial Y_{\mathrm{N}}}{\partial y}-\frac{\partial}{\partial y}\left(\rho D \frac{\partial Y_{\mathrm{N}}}{\partial y}\right)=0 .
\end{aligned}
$$

Energy:

$$
\rho u \frac{\partial\left(c_{p} T\right)}{\partial x}+\rho v \frac{\partial\left(c_{p} T\right)}{\partial y}-\frac{\partial}{\partial y}\left(\lambda \frac{\partial T}{\partial y}\right)=q w_{\mathrm{F}},
$$

where $T$ is the temperature, $c_{p}$ the specific heat, $q$ the heat of combustion per unit mass of CO, $Y$ the mass fraction, $u$ the velocity in the tangential direction $x, v$ the velocity in the normal direction $y$, and the subscripts $\mathrm{C}, \mathrm{F}, \mathrm{O}, \mathrm{P}, \mathrm{N}, \mathrm{g}, \mathrm{s}$, and $\infty$, respectively, designate carbon, carbon monoxide, oxygen, carbon dioxide, nitrogen, the gas phase, the surface, and the freestream.

In these derivations, use has been made of assumptions that the pressure and viscous heating are negligible in (4), that a single binary diffusion coefficient $D$ exists for all species pairs, that $c_{p}$ is constant, and that the $\mathrm{CO}-\mathrm{O}_{2}$ reaction can be represented by a one-step, overall, irreversible reaction with a reaction rate

$$
w_{\mathrm{F}}=\left(\nu_{i} W_{i}\right) B_{\mathrm{g}}\left(\frac{\rho Y_{\mathrm{F}}}{W_{\mathrm{F}}}\right)^{\nu_{\mathrm{F}}}\left(\frac{\rho Y_{\mathrm{O}}}{W_{\mathrm{O}}}\right)^{\nu_{\mathrm{O}}} \exp \left(-\frac{E_{\mathrm{g}}}{R^{o} T}\right),
$$

where $B$ is the frequency factor, $E$ the activation energy, $R^{o}$ the universal gas constant, $v$ the stoichiometric coefficient, and $W$ the molecular weight. We should also note that $R^{j}$ in (1) describes the curvature of the surface such that $j=1$ and 0 designate axisymmetric and two-dimensional flows, respectively, and the velocity components $u_{\infty}$ and $v_{\infty}$ of the frictionless flow outside the boundary layer are given by use of the velocity gradient $a$ as

$$
u_{\infty}=a x, \quad v_{\infty}=-(j+1) a y .
$$

2.3. Boundary Conditions. The boundary conditions for the continuity and the momentum equations are the well-known ones, expressed as

$$
\begin{aligned}
& \text { at } y=0: u=0, \quad v=v_{s}, \\
& \text { as } y \longrightarrow \infty: v=v_{\infty} .
\end{aligned}
$$


For the species conservation equations, we have in the freestream

$$
\left(Y_{\mathrm{F}}\right)_{\infty}=0, \quad\left(Y_{i}\right)_{\infty}=Y_{i, \infty} \quad(i=\mathrm{O}, \mathrm{P}, \mathrm{N}) .
$$

At the carbon surface, components transported from gas to solid by diffusion, transported away from the interface by convection, and produced/consumed by surface reactions are to be considered. Then, we have

$$
\begin{aligned}
& \left(\rho v Y_{\mathrm{F}}\right)_{\mathrm{s}}-\left(\rho D \frac{\partial Y_{\mathrm{F}}}{\partial y}\right)_{\mathrm{s}}=2 W_{\mathrm{F}}\left(\frac{\rho Y_{\mathrm{O}}}{W_{\mathrm{O}}}\right)_{\mathrm{s}} B_{\mathrm{s}, \mathrm{O}} \exp \left(-\frac{T a_{\mathrm{s}, \mathrm{O}}}{T_{\mathrm{s}}}\right) \\
& +2 W_{\mathrm{F}}\left(\frac{\rho Y_{\mathrm{P}}}{W_{\mathrm{P}}}\right)_{\mathrm{s}} B_{\mathrm{s}, \mathrm{P}} \exp \left(-\frac{T a_{\mathrm{s}, \mathrm{P}}}{T_{\mathrm{s}}}\right) \\
& \left(\rho v Y_{\mathrm{O}}\right)_{\mathrm{s}}-\left(\rho D \frac{\partial Y_{\mathrm{O}}}{\partial y}\right)_{\mathrm{s}}=-W_{\mathrm{O}}\left(\frac{\rho Y_{\mathrm{O}}}{W_{\mathrm{O}}}\right)_{\mathrm{s}} B_{\mathrm{s}, \mathrm{O}} \exp \left(-\frac{T a_{\mathrm{s}, \mathrm{O}}}{T_{\mathrm{s}}}\right), \\
& \left(\rho v Y_{\mathrm{P}}\right)_{\mathrm{s}}-\left(\rho D \frac{\partial Y_{\mathrm{P}}}{\partial y}\right)_{\mathrm{s}}=-W_{\mathrm{P}}\left(\frac{\rho Y_{\mathrm{P}}}{W_{\mathrm{P}}}\right)_{\mathrm{s}} B_{\mathrm{s}, \mathrm{P}} \exp \left(-\frac{T a_{\mathrm{s}, \mathrm{P}}}{T_{\mathrm{s}}}\right), \\
& \left(\rho v Y_{\mathrm{N}}\right)_{\mathrm{s}}-\left(\rho D \frac{\partial Y_{\mathrm{N}}}{\partial y}\right)_{\mathrm{s}}=0
\end{aligned}
$$

2.4. Nondimensional Conservation Equations. In boundary layer variables, the conservation equations for momentum, species, $i$, and energy are, respectively,

$$
\begin{gathered}
\frac{d^{3} f}{d \eta^{3}}+f \frac{d^{2} f}{d \eta^{2}}+\frac{1}{2^{j}}\left\{\frac{\rho_{\mathrm{O}}}{\rho}-\left(\frac{d f}{d \eta}\right)^{2}\right\}=0 \\
L\left(\widetilde{Y}_{\mathrm{F}}+\widetilde{Y}_{\mathrm{P}}\right)=L\left(\widetilde{Y}_{\mathrm{O}}+\widetilde{Y}_{\mathrm{P}}\right)=L\left(\widetilde{Y}_{\mathrm{P}}-\widetilde{T}\right)=L\left(\widetilde{Y}_{\mathrm{N}}\right)=0 \\
L(\widetilde{T})=-D a_{\mathrm{g}} \omega_{\mathrm{g}}
\end{gathered}
$$

where the convective-diffusive operator is defined as

$$
L=\frac{d^{2}}{d \eta^{2}}+f \frac{d}{d \eta} .
$$

The present Damköhler number for the gas-phase $\mathrm{CO}-\mathrm{O}_{2}$ reaction is given by

$$
D a_{\mathrm{g}}=\left(\frac{B_{\mathrm{g}}}{2^{j} a}\right)\left(\frac{\rho_{\infty}}{\nu_{\mathrm{P}} W_{\mathrm{P}}}\right)^{\nu_{\mathrm{F}}+v_{\mathrm{O}}-1}\left(\nu_{\mathrm{F}}\right)^{\nu_{\mathrm{F}}}\left(\nu_{\mathrm{O}}\right)^{\nu_{\mathrm{O}}},
$$

with the nondimensional reaction rate

$$
\omega_{\mathrm{g}}=\left(\frac{\widetilde{T}_{\infty}}{\widetilde{T}}\right)^{\nu_{\mathrm{F}}+\nu_{\mathrm{O}}-1}\left(\widetilde{Y}_{\mathrm{F}}\right)^{\nu_{\mathrm{F}}}\left(\widetilde{Y}_{\mathrm{O}}\right)^{\nu_{\mathrm{O}}} \exp \left(-\frac{\widetilde{T} a_{\mathrm{g}}}{\widetilde{T}}\right) .
$$

In the above, the conventional boundary-layer variables $s$ and $\eta$, related to the physical coordinates $x$ and $y$, are

$$
\begin{gathered}
s=\int_{0}^{x} \rho_{\infty}(x) \mu_{\infty}(x) u_{\infty}(x) R^{2 j} d x, \\
\eta=\frac{u_{\infty}(x) R^{j}}{\sqrt{2 s}} \int_{0}^{y} \rho(x, y) d y .
\end{gathered}
$$

The nondimensional streamfunction $f(s, \eta)$ is related to the streamfunction $\psi(x, y)$ through

$$
f(s, \eta)=\frac{\psi(x, y)}{\sqrt{2 s}}
$$

where $\psi(x, y)$ is defined by

$$
\rho u R^{j}=\frac{\partial \psi}{\partial y}, \quad \rho v R^{j}=-\frac{\partial \psi}{\partial x}
$$

such that the continuity equation is automatically satisfied. Variables and parameters used are as follows:

$$
\begin{array}{cl}
\widetilde{T}=\frac{T}{q /\left(c_{p} \alpha_{\mathrm{F}}\right)}, & \widetilde{T} a=\frac{E / R^{o}}{q /\left(c_{p} \alpha_{\mathrm{F}}\right)}, \\
\alpha_{\mathrm{F}}=\frac{\nu_{\mathrm{P}} W_{\mathrm{P}}}{\nu_{\mathrm{F}} W_{\mathrm{F}}}, & \widetilde{Y}_{\mathrm{F}}=\frac{\nu_{\mathrm{P}} W_{\mathrm{P}}}{\nu_{\mathrm{F}} W_{\mathrm{F}}} Y_{\mathrm{F}}, \\
\widetilde{Y}_{\mathrm{O}}=\frac{\nu_{\mathrm{P}} W_{\mathrm{P}}}{\nu_{\mathrm{O}} W_{\mathrm{O}}}, \quad \widetilde{Y}_{\mathrm{N}}=Y_{\mathrm{N}}, \quad \delta=\frac{W_{\mathrm{P}}}{W_{\mathrm{C}}} .
\end{array}
$$

Here, use has been made of an additional assumption that the Prandtl and Schmidt numbers are unity. Since we adopt the ideal-gas equation of state under an assumption of constant, average molecular weight across the boundary layer, the term $\left(\rho_{\infty} / \rho\right)$ in $(10)$ can be replaced by $\left(T / T_{\infty}\right)$. As for the constant $\rho \mu$ assumption, while enabling considerable simplification, it introduces $50 \%-70 \%$ errors in the transport properties of the gas in the present temperature range. However, these errors are acceptable for far greater errors in the chemical reaction rates. Furthermore, they are anticipated to be reduced due to the change of composition by the chemical reactions.

The boundary conditions for (10) are

$$
f(0)=f_{s}, \quad\left(\frac{d f}{d \eta}\right)_{s}=0, \quad\left(\frac{d f}{d \eta}\right)_{\infty}=1,
$$

whereas those for (11) and (12) are

$$
\begin{aligned}
& \text { at } \eta=0: \widetilde{T}=\widetilde{T}_{\mathrm{s}}, \quad \widetilde{Y}_{i}=\left(\widetilde{Y}_{i}\right)_{\mathrm{s}} \quad(i=\mathrm{F}, \mathrm{O}, \mathrm{P}, \mathrm{N}), \\
& \text { as } \eta \longrightarrow \infty: \\
& \widetilde{T}=\widetilde{T}_{\infty}, \quad \widetilde{Y}_{\mathrm{F}}=0, \quad \widetilde{Y}_{i}=\left(\widetilde{Y}_{i}\right)_{\infty} \quad(i=\mathrm{O}, \mathrm{P}, \mathrm{N}),
\end{aligned}
$$


which are to be supplemented by the following conservation relations at the surface:

$$
\begin{aligned}
&-\left(\frac{d \widetilde{Y}_{\mathrm{F}}}{d \eta}\right)_{\mathrm{s}}+\left(-f_{\mathrm{s}}\right) \widetilde{Y}_{\mathrm{F}, \mathrm{s}}=\delta\left(-f_{\mathrm{s}, \mathrm{O}}\right)+2 \delta\left(-f_{\mathrm{s}, \mathrm{P}}\right) \\
&=\delta\left(-f_{\mathrm{s}}\right)+\delta\left(-f_{\mathrm{s}, \mathrm{P}}\right), \\
&-\left(\frac{d \widetilde{Y}_{\mathrm{O}}}{d \eta}\right)_{\mathrm{s}}+\left(-f_{\mathrm{s}}\right) \widetilde{Y}_{\mathrm{O}, \mathrm{s}}=-\delta\left(-f_{\mathrm{s}, \mathrm{O}}\right) \\
&=-\delta\left(-f_{\mathrm{s}}\right)+\delta\left(-f_{\mathrm{s}, \mathrm{P}}\right), \\
&-\left(\frac{d \widetilde{Y}_{\mathrm{P}}}{d \eta}\right)_{\mathrm{s}}+\left(-f_{\mathrm{s}}\right) \widetilde{Y}_{\mathrm{P}, \mathrm{s}}=-\delta\left(-f_{\mathrm{s}, \mathrm{P}}\right) \\
&-\left(\frac{d \widetilde{Y}_{\mathrm{N}}}{d \eta}\right)_{\mathrm{s}}+\left(-f_{\mathrm{s}}\right) \widetilde{Y}_{\mathrm{N}, \mathrm{s}}=0,
\end{aligned}
$$

where

$$
\begin{gathered}
\delta\left(-f_{\mathrm{s}}\right)=\delta\left(-f_{\mathrm{s}, \mathrm{O}}\right)+\delta\left(-f_{\mathrm{s}, \mathrm{P}}\right)=A_{\mathrm{s}, \mathrm{O}} \widetilde{Y}_{\mathrm{O}, \mathrm{s}}+A_{\mathrm{s}, \mathrm{P}} \widetilde{Y}_{\mathrm{P}, \mathrm{s}}, \\
A_{\mathrm{s}, \mathrm{O}} \equiv D a_{\mathrm{s}, \mathrm{O}}\left(\frac{\widetilde{T}_{\infty}}{\widetilde{T}_{\mathrm{s}}}\right) \exp \left(-\frac{\widetilde{T} a_{\mathrm{s}, \mathrm{O}}}{\widetilde{T}_{\mathrm{s}}}\right), \\
D a_{\mathrm{s}, \mathrm{O}} \equiv \frac{B_{\mathrm{s}, \mathrm{O}}}{\sqrt{2^{j} a\left(\mu_{\infty} / \rho_{\infty}\right)}}, \\
A_{\mathrm{s}, \mathrm{P}} \equiv D a_{\mathrm{s}, \mathrm{P}}\left(\frac{\widetilde{T}_{\infty}}{\widetilde{T}_{\mathrm{s}}}\right) \exp \left(-\frac{\widetilde{T} a_{\mathrm{s}, \mathrm{P}}}{\widetilde{T}_{\mathrm{s}}}\right), \\
D a_{\mathrm{s}, \mathrm{P}} \equiv \frac{B_{\mathrm{s}, \mathrm{P}}}{\sqrt{2^{j} a\left(\mu_{\infty} / \rho_{\infty}\right)}},
\end{gathered}
$$

and $D a_{\mathrm{s}, \mathrm{O}}$ and $D a_{\mathrm{s}, \mathrm{P}}$ are the present surface Damköhler numbers, based only on the frequency factors for the $\mathrm{C}-\mathrm{O}_{2}$ and $\mathrm{C}-\mathrm{CO}_{2}$ reactions, respectively. Here, these heterogeneous reactions are assumed to be first order, for simplicity and analytical convenience. As for the kinetic expressions for nonpermeable solid carbon, it is considered that they incorporate effects of porosity and/or internal surface area, while surface reactions are generally controlled by combinations of chemical kinetics and pore diffusions.

For self-similar flows, the normal velocity $v_{\mathrm{s}}$ at the surface is expressible in terms of $\left(-f_{\mathrm{s}}\right)$ by

$$
(\rho v)_{\mathrm{s}}=\left(-f_{\mathrm{s}}\right) \sqrt{2^{j} a \rho_{\infty} \mu_{\infty}} .
$$

If we remember the fact that the mass burning rate of solid carbon is given by $\dot{m}=(\rho v)_{\mathrm{s}}$, which is equivalent to the definition of the combustion rate $\left[\mathrm{kg} /\left(\mathrm{m}^{2} \cdot \mathrm{s}\right)\right]$, we see that the streamfunction $\left(-f_{\mathrm{s}}\right)$ can be identified as the nondimensional combustion rate. Note also that the surface reactions are less sensitive to velocity gradient variations than the gas-phase reaction because $D a_{\mathrm{s}} \sim a^{-1 / 2}$ while $D a_{\mathrm{g}} \sim a^{-1}$.
2.5. Coupling Functions. With the boundary conditions for species, cast in the specific forms of (22) to (24), the coupling functions for the present system are given by

$$
\begin{gathered}
\widetilde{Y}_{\mathrm{F}}+\widetilde{Y}_{\mathrm{P}}=\frac{\left(\widetilde{Y}_{\mathrm{P}, \infty}+\delta \beta\right)+\left(\widetilde{Y}_{\mathrm{P}, \infty}-\delta\right) \beta \xi}{1+\beta}, \\
\widetilde{Y}_{\mathrm{O}}+\widetilde{Y}_{\mathrm{P}}=\frac{\left(\widetilde{Y}_{\mathrm{O}, \infty}+\widetilde{Y}_{\mathrm{P}, \infty}-\delta \beta\right)+\left(\widetilde{Y}_{\mathrm{O}, \infty}+\widetilde{Y}_{\mathrm{P}, \infty}+\delta\right) \beta \xi}{1+\beta}, \\
\widetilde{Y}_{\mathrm{O}}+\widetilde{T}^{=} \widetilde{Y}_{\mathrm{O}, \mathrm{s}}+\widetilde{T}_{\mathrm{s}}+\left(\widetilde{Y}_{\mathrm{O}, \infty}-\widetilde{Y}_{\mathrm{O}, \mathrm{s}}+\widetilde{T}_{\infty}-\widetilde{T}_{\mathrm{s}}\right) \xi \\
\widetilde{Y}_{\mathrm{O}, \mathrm{s}}=\frac{\widetilde{Y}_{\mathrm{O}, \infty}+\widetilde{T}_{\infty}-\widetilde{T}_{\mathrm{s}}-\gamma}{1+\beta+A_{\mathrm{s}, \mathrm{O}}\left[\beta /\left(-f_{\mathrm{s}}\right)\right]}, \\
\widetilde{T}_{=} \widetilde{Y}_{\mathrm{P}, \mathrm{s}}-\widetilde{T}_{\mathrm{s}}+\left(\widetilde{Y}_{\mathrm{P}, \infty}-\widetilde{Y}_{\mathrm{P}, \mathrm{s}}-\widetilde{T}_{\infty}+\widetilde{T}_{\mathrm{s}}\right) \xi \\
\widetilde{Y}_{\mathrm{P}, \mathrm{s}}=\frac{\widetilde{Y}_{\mathrm{P}, \infty}-\widetilde{T}_{\infty}+\widetilde{T}_{\mathrm{s}}+\gamma}{1+\beta+A_{\mathrm{s}, \mathrm{P}}\left[\beta /\left(-f_{\mathrm{s}}\right)\right]}, \\
\widetilde{Y}_{\mathrm{N}}=\widetilde{Y}_{\mathrm{N}, \infty} \frac{1+\beta \xi}{1+\beta},
\end{gathered}
$$

where

$$
\begin{gathered}
\xi=\frac{\int_{0}^{\eta} \exp \left(-\int_{0}^{\eta} f d \eta\right) d \eta}{\int_{0}^{\infty} \exp \left(-\int_{0}^{\eta} f d \eta\right) d \eta}, \\
\gamma=\frac{\left(\widetilde{T}^{\prime}\right)_{\mathrm{s}}}{\left(\xi^{\prime}\right)_{\mathrm{s}}}, \quad \beta=\frac{\left(-f_{\mathrm{s}}\right)}{\left(\xi^{\prime}\right)_{\mathrm{s}}}, \\
\left(\xi^{\prime}\right)_{\mathrm{s}}=\frac{1}{\int_{0}^{\infty} \exp \left(-\int_{0}^{\eta} f d \eta\right) d \eta},
\end{gathered}
$$

and a prime indicates $d / d \eta$. Using the new independent variable $\xi$, the energy conservation (12) becomes

$$
\left(\frac{d^{2} \widetilde{T}}{d \xi^{2}}\right)=-\frac{D a_{\mathrm{g}} \omega_{\mathrm{g}}}{(d \xi / d \eta)^{2}}
$$

Therefore, the equations to be solved are (10) and (35), subject to the boundary conditions in (20) and

$$
(\widetilde{T})_{\xi=0}=\widetilde{T}_{s}, \quad(\widetilde{T})_{\xi=1}=\widetilde{T}_{\infty}
$$

by use of $\left(-f_{\mathrm{s}}\right)$ given by (26) and the coupling functions in (29) to (32). Key parameters in solving those are $D a_{\mathrm{g}}, D a_{\mathrm{s}, \mathrm{O}}$, $D a_{\mathrm{s}, \mathrm{P}}$, and $\left(-f_{\mathrm{s}}\right)$.

It may be informative to note that the parameter $\beta$, introduced as $\left(-f_{\mathrm{s}}\right) /\left(\xi^{\prime}\right)_{\mathrm{s}}$ in the formulation, and indispensable in obtaining combustion rate $\left(-f_{s}\right)$, coincides with the conventional transfer number presented by Spalding [26]. This has already been demonstrated by considering elemental carbon, $\left(W_{\mathrm{C}} / W_{\mathrm{F}}\right) Y_{\mathrm{F}}+\left(W_{\mathrm{C}} / W_{\mathrm{P}}\right) Y_{\mathrm{P}}$, taken as the transferred 
substance, and by evaluating driving force and resistance, determined, respectively, by the transfer rate in the gas phase and the ejection rate at the surface $[27,28]$; that is,

$$
\begin{gathered}
\frac{\left(W_{\mathrm{C}} Y_{\mathrm{F}} / W_{\mathrm{F}}+W_{\mathrm{C}} Y_{\mathrm{P}} / W_{\mathrm{P}}\right)_{\mathrm{s}}-\left(W_{\mathrm{C}} Y_{\mathrm{F}} / W_{\mathrm{F}}+W_{\mathrm{C}} Y_{\mathrm{P}} / W_{\mathrm{P}}\right)_{\infty}}{1-\left(W_{\mathrm{C}} Y_{\mathrm{F}} / W_{\mathrm{F}}+W_{\mathrm{C}} Y_{\mathrm{P}} / W_{\mathrm{P}}\right)_{\mathrm{s}}} \\
=\frac{\left(\widetilde{Y}_{\mathrm{F}}+\widetilde{Y}_{\mathrm{P}}\right)_{\mathrm{s}}-\left(\widetilde{Y}_{\mathrm{F}}+\widetilde{Y}_{\mathrm{P}}\right)_{\infty}}{\delta-\left(\widetilde{Y}_{\mathrm{F}}+\widetilde{Y}_{\mathrm{P}}\right)_{\mathrm{s}}} \equiv \beta .
\end{gathered}
$$

Note that use has been made of the coupling function $\widetilde{Y}_{\mathrm{F}}+\widetilde{Y}_{\mathrm{P}}$ in (29) in deriving the final relation.

\section{Combustion Behavior in the Limiting Cases}

Here, we discuss analytical solutions for some limiting cases of the gas-phase reaction, since several limiting solutions regarding the intensity of the gas-phase $\mathrm{CO}-\mathrm{O}_{2}$ reaction can readily be identified from the coupling functions. In addition, important characteristics, indispensable for fundamental understanding, are obtainable.

3.1. Frozen Mode. When the gas-phase $\mathrm{CO}-\mathrm{O}_{2}$ reaction is completely frozen, the solution of the energy conservation (12) readily yields

$$
\widetilde{T}=\widetilde{T}_{\mathrm{s}}+\gamma \xi ; \quad \gamma=\widetilde{T}_{\infty}-\widetilde{T}_{\mathrm{s}}
$$

Evaluating (31) and (32) at $\xi=0$, to obtain the surface concentrations of $\mathrm{O}_{2}$ and $\mathrm{CO}_{2}$, and substituting them into (26), we obtain an implicit expression for the combustion rate $\left(-f_{\mathrm{s}}\right)$ as

$$
\begin{aligned}
\delta\left(-f_{\mathrm{s}}\right)= & A_{\mathrm{s}, \mathrm{O}} \frac{\tilde{Y}_{\mathrm{O}, \infty}}{1+\beta+A_{\mathrm{s}, \mathrm{O}}\left[\beta /\left(-f_{\mathrm{s}}\right)\right]} \\
& +A_{\mathrm{s}, \mathrm{P}} \frac{\tilde{Y}_{\mathrm{P}, \infty}}{1+\beta+A_{\mathrm{s}, \mathrm{P}}\left[\beta /\left(-f_{\mathrm{s}}\right)\right]},
\end{aligned}
$$

which is to be solved numerically from (10), because of the density coupling. The combustion rate in the diffusion controlled regime becomes the highest with satisfying the following condition:

$$
\beta_{\max }=\frac{\widetilde{Y}_{\mathrm{O}, \infty}+\tilde{Y}_{\mathrm{P}, \infty}}{\delta} .
$$

3.2. Flame-Detached Mode. When the gas-phase $\mathrm{CO}-\mathrm{O}_{2}$ reaction occurs infinitely fast, two types of flame-sheet burning modes are possible. One involves a detached flamesheet, situated away from the surface, and the other an attached flame sheet, situated on the surface. The flamedetached mode is defined by

$$
\tilde{Y}_{\mathrm{O}}\left(0 \leq \xi \leq \xi_{\mathrm{f}}\right)=\tilde{Y}_{\mathrm{F}}\left(\xi_{\mathrm{f}} \leq \xi \leq \infty\right)=0
$$

By use of the coupling functions in (29) to (32), it can be shown that

$$
\begin{gathered}
\delta\left(-f_{\mathrm{s}}\right)=A_{\mathrm{s}, \mathrm{P}} \frac{\widetilde{Y}_{\mathrm{O}, \infty}+\widetilde{Y}_{\mathrm{P}, \infty}-\delta \beta}{1+\beta}, \\
\widetilde{T}_{\mathrm{f}}=\widetilde{T}_{\mathrm{s}}+\left(\widetilde{Y}_{\mathrm{O}, \infty}+\widetilde{T}_{\infty}-\widetilde{T}_{\mathrm{s}}\right) \xi_{\mathrm{f}}, \\
\xi_{\mathrm{f}}=\frac{2 \delta \beta-\widetilde{Y}_{\mathrm{O}, \infty}}{\left(2 \delta+\widetilde{Y}_{\mathrm{O}, \infty}\right) \beta} .
\end{gathered}
$$

Once $\left(-f_{\mathrm{s}}\right)$ is determined from (42) and (10), $\xi_{\mathrm{f}}$ can readily be evaluated, yielding the temperature distribution as

$$
\begin{gathered}
0 \leq \xi \leq \xi_{\mathrm{f}}: \widetilde{T}=\widetilde{T}_{\mathrm{s}}+\left(\widetilde{Y}_{\mathrm{O}, \infty}+\widetilde{T}_{\infty}-\widetilde{T}_{\mathrm{s}}\right) \xi, \\
\xi_{\mathrm{f}} \leq \xi \leq \infty: \\
\widetilde{T}=\widetilde{T}_{\infty}-\left\{\widetilde{T}_{\infty}-\widetilde{T}_{\mathrm{s}}+\left(\frac{\widetilde{Y}_{\mathrm{O}, \infty}-2 \delta \beta}{1+\beta}\right)\right\}(1-\xi) .
\end{gathered}
$$

In addition, the infinitely large $D a_{\mathrm{g}}$ yields the following important characteristics, as reported by Tsuji and Matsui [17].

(1) The quantities $Y_{\mathrm{F}}$ and $Y_{\mathrm{O}}$ in the reaction rate $\omega_{\mathrm{g}}$ in (15) become zero, suggesting that fuel and oxygen do not coexist throughout the boundary layer and that the diffusion flame becomes a flame sheet.

(2) In the limit of an infinitesimally thin reaction zone, by conducting an integration of the coupling function for $\mathrm{CO}$ and $\mathrm{O}_{2}$ across the zone, bounded between $\eta_{\mathrm{f}-}<\eta<\eta_{\mathrm{f}+}$, where $\eta_{\mathrm{f}}$ is the location of flame sheet, we have

$$
-\left(\frac{d \widetilde{Y}_{\mathrm{F}}}{d \eta}\right)_{\mathrm{f}-}=\left(\frac{d \tilde{Y}_{\mathrm{O}}}{d \eta}\right)_{\mathrm{f}+}
$$

or

$$
-\left(\frac{d Y_{\mathrm{F}}}{d \eta}\right)_{\mathrm{f}-}=\frac{\nu_{\mathrm{F}} W_{\mathrm{F}}}{v_{\mathrm{O}} W_{\mathrm{O}}}\left(\frac{d Y_{\mathrm{O}}}{d \eta}\right)_{\mathrm{f}+},
$$

suggesting that fuel and oxidizer must flow into the flame surface in stoichiometric proportions. Here, the subscripts $\mathrm{f}+$ and $\mathrm{f}-$, respectively, designate the oxygen and fuel sides of the flame. Note that in deriving (45), use has been made of an assumption that values of the individual quantities, such as the streamfunction $f$ and species mass-fraction $Y_{i}$, can be continuous across the flame.

(3) Similarly, by evaluating the coupling function for $\mathrm{CO}$ and enthalpy at the flame sheet, we have

$$
\left(\frac{d \widetilde{T}}{d \eta}\right)_{\mathrm{f}-}-\left(\frac{d \widetilde{T}}{d \eta}\right)_{\mathrm{f}+}=-\left(\frac{d \widetilde{Y}_{\mathrm{F}}}{d \eta}\right)_{\mathrm{f}-}
$$

or

$$
\lambda\left(\frac{d T}{d \eta}\right)_{\mathrm{f}-}-\lambda\left(\frac{d T}{d \eta}\right)_{\mathrm{f}+}=-q \rho D\left(\frac{d Y_{\mathrm{F}}}{d \eta}\right)_{\mathrm{f}-},
$$


suggesting that the amount of heat generated is equal to the heat conducted away to both sides of the reaction zone.

3.3. Flame-Attached Mode. When the surface reactivity is decreased by decreasing the surface temperature, then the detached flame sheet moves towards the surface until it is contiguous to it $\left(\xi_{\mathrm{f}}=0\right)$. This critical state is given by the condition

$$
\beta_{\mathrm{a}}=\frac{\tilde{Y}_{\mathrm{O}, \infty}}{2 \delta},
$$

obtained from (43), and defines the transition from the detached to the attached mode of the flame. Subsequent combustion with the flame-attached mode is characterized by $Y_{\mathrm{F}, \mathrm{s}}=0$ and $Y_{\mathrm{O}, \mathrm{s}} \geq 0[20,22,29]$, with the gas-phase temperature profile

$$
\widetilde{T}=\widetilde{T}_{\mathrm{s}}+\left(\widetilde{T}_{\infty}-\widetilde{T}_{\mathrm{s}}\right) \xi
$$

given by the same relation as that for the frozen mode, because all gas-phase reaction is now confined at the surface. By using the coupling functions from (29) to (32) with $Y_{\mathrm{F}, \mathrm{s}}=$ 0 , it can be shown that

$$
\delta\left(-f_{\mathrm{s}}\right)=A_{\mathrm{s}, \mathrm{O}} \frac{\tilde{Y}_{\mathrm{O}, \infty}-2 \delta \beta}{1+\beta}+A_{\mathrm{s}, \mathrm{P}} \frac{\tilde{Y}_{\mathrm{P}, \infty}+\delta \beta}{1+\beta},
$$

which is also to be solved numerically from (10). The maximum combustion rate of this mode occurs at the transition state in (47), which also corresponds to the minimum combustion rate of the flame-detached mode.

3.4. Diffusion-Limited Combustion Rate. The maximum, diffusion-limited transfer number of the system can be achieved through one of the two limiting situations. The first appears when both of the surface reactions occur infinitely fast such that $Y_{\mathrm{O}, \mathrm{s}}$ and $Y_{\mathrm{P}, \mathrm{s}}$ both vanish in the limit of the frozen mode, yielding (40). The second appears when the surface $\mathrm{C}-\mathrm{CO}_{2}$ reaction occurs infinitely fast in the limit of the flame-detached mode, which again yields (40). It is of interest to note that in the first situation the reactivity of the gas-phase $\mathrm{CO}-\mathrm{O}_{2}$ reaction is irrelevant, whereas in the second the reactivity of the surface $\mathrm{C}-\mathrm{O}_{2}$ reaction is irrelevant. While the transfer numbers $\beta$ are the same in both cases, the combustion rates, thereby the oxygen supply rates, are slightly different from each other, because of the different density coupling, related to the flame structures. Note that the limiting solutions identified herein provide the counterparts of those previously derived $[22,29,30]$ for the carbon particle and generalize the solution of Matsui and Tsuji [21] with including the surface $\mathrm{C}-\mathrm{CO}_{2}$ reaction.

\section{Combustion Rate and the CO Flame}

A momentary reduction in the combustion rate, reported in theoretical works $[19,21-23,31,32]$, can actually be exaggerated by the appearance of $\mathrm{CO}$ flame in the gas phase, bringing about a change of the dominant surface reactions from the faster $\mathrm{C}-\mathrm{O}_{2}$ reaction to the slower $\mathrm{C}-\mathrm{CO}_{2}$ reaction, due to an intimate coupling between the surface and gasphase reactions. In spite of this theoretical accomplishment, there are very few experimental data that can support it.

In the literature, in general, emphasis has been put on examination of the surface reactivities with gaseous oxidizers, such as $\mathrm{O}_{2}, \mathrm{CO}_{2}$, and $\mathrm{H}_{2} \mathrm{O}$ (cf. [10]), although surface reactivities on the same solid carbon are limited [33-35]. As for the gas-phase $\mathrm{CO}-\mathrm{O}_{2}$ reactivity, which is sensitive to the $\mathrm{H}_{2} \mathrm{O}$ concentration, main concern has been put on that of the CO flame [36], called as the "strong" CO oxidation, which is, however, far from the situation over the burning carbon, especially for that prior to the appearance of CO flame, because some of the elementary reactions are too slow to sustain the "strong" CO oxidation. Furthermore, it has been quite rare to conduct experimental studies from the viewpoint that there exist interactions between chemical reactions and flow, so that studies have mainly been confined to obtaining combustion rate [33, 34, 37-39].

4.1. Combustion Rate and Ignition Surface Temperature. Here, experimental results of Visser and Adomeit [34] for the carbon combustion are first presented, which are closely related to the coupled nature of the surface and gas-phase reactions. In their experiment, the oxidizer flow at room temperature, after being set for a flow rate and various species concentrations, such as $\mathrm{O}_{2}$ and $\mathrm{H}_{2} \mathrm{O}$, issued into the atmosphere with a uniform velocity (up to $9.5 \mathrm{~m} / \mathrm{s}$ ), and impinged on a graphite hemisphere to establish an axisymmetric stagnation flow. This flowfield is well established and is specified uniquely by the velocity gradient $a\left(=3 V_{\infty} / d\right)$, where $V_{\infty}$ is the freestream velocity and $d$ the diameter of graphite sphere or hemisphere [40]. The spherical test specimen was heated by an electromagnetic high frequency generator and the surface temperature was measured by a radiation thermometer. During each experimental run, the test specimen was set to burn in oxidizer flow at constant surface temperature. Since the surface temperature is kept constant with external heating, quasi-steady combustion can be accomplished. The experiment involved taking pictures of the test specimen in the forward stagnation region and analyzing them to obtain surface regression rate, which was used to determine the combustion rate. Note that use has been made of the value, evaluated by use of the well-known relation $a=3 V_{\infty} / d$, as far as the velocity gradient is concerned, even though it is specified in another way in the literature.

Figure 1(a) shows the combustion rate in oxidizer flow of $170 \mathrm{~s}^{-1}$ with the $\mathrm{O}_{2}$ mass fraction of $0.7[34,41]$, as a function of the surface temperature, when the $\mathrm{H}_{2} \mathrm{O}$ mass fraction is 0.0002 . The combustion rate increases with increasing surface temperature, up to a certain surface temperature. The combustion in this temperature range is anticipated to be that with negligible $\mathrm{CO}$ oxidation, and hence the combustion rate in the frozen mode can fairly predict the experimental results. A further increase in the surface temperature causes the momentary reduction in the combustion rate, because 


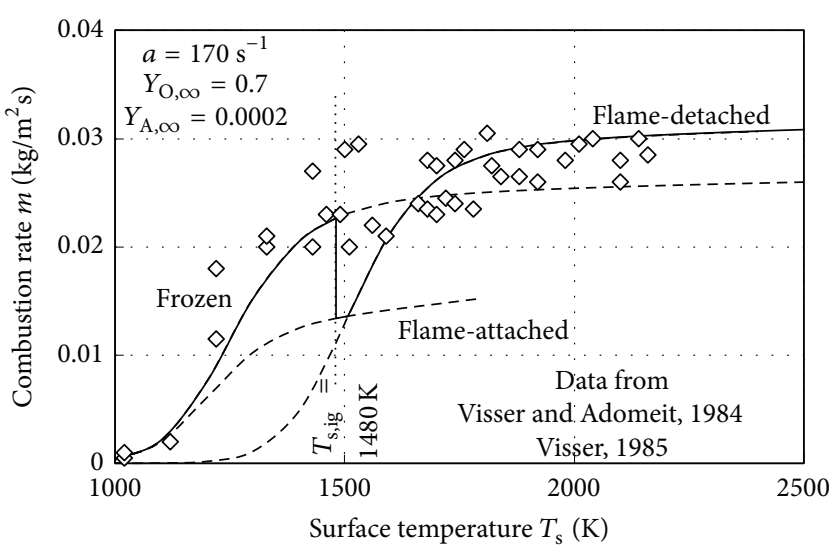

(a)

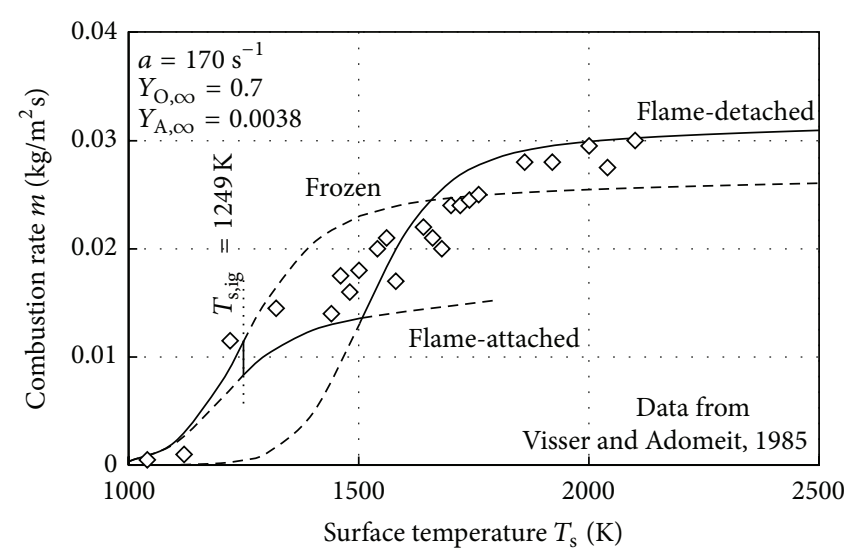

(b)

FIGURE 1: Combustion rate of the graphite hemisphere in oxidizer flow with the velocity gradient of $170 \mathrm{~s}^{-1}$, as a function of the surface temperature: (a) for the $\mathrm{O}_{2}$ mass-fraction $Y_{\mathrm{O}, \infty}=0.7$ and the $\mathrm{H}_{2} \mathrm{O}$ mass-fraction $Y_{\mathrm{A}, \infty}=0.0002$, (b) for $Y_{\mathrm{O}, \infty}=0.7$ and $Y_{\mathrm{A}, \infty}=0.0038$. Data points are experimental [34,41] and curves are calculated from the theory in [23]. The ignition surface-temperature $T_{\mathrm{s}, \mathrm{ig}}$ is calculated, based on the ignition analysis [32].

appearance of the $\mathrm{CO}$ flame alters the dominant surface reaction from the $\mathrm{C}-\mathrm{O}_{2}$ reaction to the $\mathrm{C}-\mathrm{CO}_{2}$ reaction. The surface temperature when the $\mathrm{CO}$ flame first appears is called as the ignition surface temperature [32]. Above the ignition surface temperature, the combustion is in the flame-detached mode with the "strong" CO oxidation. The solid curve is the predicted combustion rate with the surface kinetic parameters as follows: for the $\mathrm{C}-\mathrm{CO}_{2}$ reaction, $B_{\mathrm{s}, \mathrm{P}}=$ $1.5 \times 10^{8} \mathrm{~m} / \mathrm{s}$ and $E_{\mathrm{s}, \mathrm{P}} / R=3.1 \times 10^{4} \mathrm{~K}$, reported, while for the $\mathrm{C}-\mathrm{O}_{2}$ reaction, $B_{\mathrm{s}, \mathrm{O}}=4.1 \times 10^{6} \mathrm{~m} / \mathrm{s}$ and $E_{\mathrm{s}, \mathrm{O}} / R=$ $2.1 \times 10^{4} \mathrm{~K}$, used in another work [42], because of a lack of those reported. In numerical calculations, use has been made of the formulation, presented in Section 2, as well as the explicit combustion-rate expressions, to be explained in Section 5, for convenience. Values of thermophysical properties are those for oxygen at $T_{\infty}=32 \mathrm{~K}$, which yields $\rho_{\infty} \mu_{\infty}=$ $2.63 \times 10^{-5} \mathrm{~kg}^{2} /\left(\mathrm{m}^{4} \cdot \mathrm{s}\right)$ and $\mu_{\infty} / \rho_{\infty}=1.83 \times 10^{-5} \mathrm{~m}^{2} / \mathrm{s}$, just for simplicity.

It may be informative to note that a decrease in the combustion rate, observed at temperatures between $1500 \mathrm{~K}$ and $2000 \mathrm{~K}$, has generally been called as the "negative temperature coefficient" of the combustion rate, which has also been a research subject in the field of carbon combustion. Nagle and Strickland-Constable [43] used the "site" theory to explain the peak rate, while Yang and Steinberg [44] attributed the peak rate to the change of reaction depth at constant activation energy. Other entries relevant to the "negative temperature coefficient" can be found in some survey papers $[10,11]$. However, another explanation can be made, as will be examined in the next section, that this phenomenon can be induced by the appearance of $\mathrm{CO}$ flame, established over the burning carbon, thereby the dominant surface reaction has been altered from the $\mathrm{C}-\mathrm{O}_{2}$ reaction to the $\mathrm{C}-\mathrm{CO}_{2}$ reaction $[28,42,45,46]$.

The same trend is also observed in humid oxidizer-flow of $170 \mathrm{~s}^{-1}$, as shown in Figure 1(b). The ignition surface temperature can be reduced, because of the increased humidity

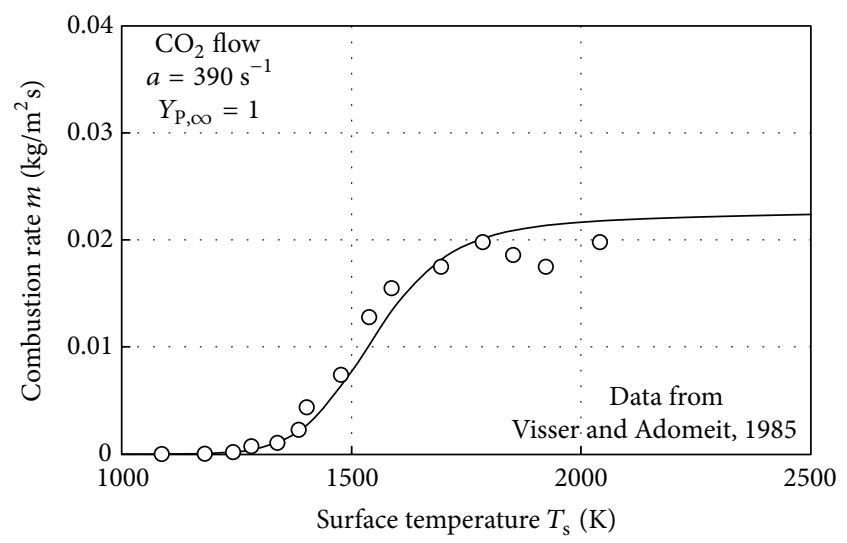

FIGURE 2: Combustion rate of the graphite hemisphere in $\mathrm{CO}_{2}$-flow with the velocity gradient of $390 \mathrm{~s}^{-1}$, as a function of the surface temperature. Data points are experimental [34] and the curve is calculated from the theory in [23].

that can facilitate the establishment of $\mathrm{CO}$ flame. Nonetheless, because of a small difference between combustion rates before and after the ignition of $\mathrm{CO}$ flame, the abrupt change in the combustion rate does not appear clearly for this case.

Figure 2 shows the combustion rate in $\mathrm{CO}_{2}$ flow of $390 \mathrm{~s}^{-1}$ [34], as a function of the surface temperature. The combustion rate increases monotonically with increasing surface temperature, suggesting appropriateness of the surface kinetic parameters for the $\mathrm{C}-\mathrm{CO}_{2}$ reaction, reported.

4.2. Establishment of the CO Flame. While studies relevant to the ignition/extinction of CO flame over the burning carbon are of obvious practical utility in evaluating protection properties from oxidation in reentry vehicles, as well as the combustion of coal/char, they also command fundamental interests because of the simultaneous existence of the surface and gas-phase reactions with intimate coupling $[21,22,34]$. 
As mentioned in the previous section, at the same surface temperature, the combustion rate is expected to be momentarily reduced upon ignition because establishment of the $\mathrm{CO}$ flame in the gas phase can change the dominant surface reactions from the faster $\mathrm{C}-\mathrm{O}_{2}$ reaction to the slower $\mathrm{C}-\mathrm{CO}_{2}$ reaction. By the same token, the combustion rate is expected to momentarily increase upon extinction. These concepts are not intuitively obvious without considering the coupled nature of the gas-phase and surface reactions.

Fundamentally, the ignition/extinction of CO flame in carbon combustion must necessarily be described by the seminal analysis, done by Liñán [47] for the ignition, extinction, and structure of diffusion flames, as indicated by Matalon [48-50]. Specifically, as the flame temperature increases from the surface temperature to the adiabatic flame temperature, there appears a nearly frozen regime, a partialburning regime, a premixed-flame regime, and finally a nearequilibrium regime. Ignition can be described in the nearlyfrozen regime, while extinction in the other three regimes.

For carbon combustion, Matalon [49] analytically obtained an explicit ignition criterion when the $\mathrm{O}_{2}$ mass fraction at the surface is $\mathrm{O}(\mathrm{l})$. When this concentration is $\mathrm{O}(\varepsilon)$, the appropriate, reduced governing equation and the boundary conditions were also identified [50]. Here, putting emphasis on the ignition of CO flame over the burning carbon, an attempt has first been made to extend the previous theoretical studies, so as to include analytical derivations of various criteria governing the ignition, with arbitrary $\mathrm{O}_{2}$ concentration at the surface. Note that these derivations are successfully conducted, by virtue of the generalized speciesenthalpy coupling functions $[22,23]$, identified in the previous Section. Furthermore, it may be noted that the ignition analysis is especially relevant to situations where the surface $\mathrm{O}_{2}$ concentration is $\mathrm{O}(\varepsilon)$ because in order for gas-phase reaction to be initiated, sufficient amount of carbon monoxide should be generated. This requires a reasonably fast surface reaction and thereby low $\mathrm{O}_{2}$ concentration. The second objective is to conduct experimental comparisons, relevant to the ignition of CO-flame over a carbon hemisphere in an oxidizing stagnation flow, at various surface temperatures of the test specimen, freestream velocity gradients, and $\mathrm{O}_{2}$ concentrations.

4.3. Asymptotic Analysis for the Ignition. Here, we intend to obtain an explicit ignition criterion without restricting the order of magnitude of the $\mathrm{O}_{2}$ concentration, $Y_{\mathrm{O}, \mathrm{s}}$. First, we note that in the limit of $T a_{\mathrm{g}} \rightarrow \infty$, the completely frozen solutions for (11) and (12) are

$$
\begin{gathered}
(\widetilde{T})_{0}=\widetilde{T}_{\mathrm{s}}+\left(\widetilde{T}_{\infty}-\widetilde{T}_{\mathrm{s}}\right) \xi \\
\left(\widetilde{Y}_{i}\right)_{0}=\widetilde{Y}_{i, \mathrm{~s}}+\left(\widetilde{Y}_{i, \infty}-\widetilde{Y}_{i, \mathrm{~s}}\right) \xi \quad(i=\mathrm{F}, \mathrm{O}, \mathrm{P}) .
\end{gathered}
$$

For finite but large values of $T a_{\mathrm{g}}$, weak chemical reaction occurs in a thin region next to the carbon surface when the surface temperature is moderately high and exceeds the ambient temperature. Since the usual carbon combustion proceeds under this situation, corresponding to the condition [47] of

$$
\widetilde{T}_{\mathrm{s}}+\widetilde{Y}_{\mathrm{F}, \mathrm{s}}>\widetilde{T}_{\infty}
$$

we define the inner temperature distribution as

$$
\begin{aligned}
(\widetilde{T})_{\text {in }} & =(\widetilde{T})_{0}+\varepsilon \widetilde{T}_{\mathrm{s}} \lambda \theta(\xi)+\mathrm{O}\left(\varepsilon^{2}\right) \\
& =\widetilde{T}_{\mathrm{s}}[1-\varepsilon(\chi-\lambda \theta)]+\mathrm{O}\left(\varepsilon^{2}\right)
\end{aligned}
$$

where

$$
\varepsilon=\frac{\widetilde{T}_{\mathrm{s}}}{\widetilde{T} a_{\mathrm{g}}}, \quad \lambda=\frac{\widetilde{Y}_{\mathrm{O}, \infty}}{\widetilde{T}_{\mathrm{s}}-\widetilde{T}_{\infty}}, \quad \xi=\varepsilon\left(\frac{\widetilde{T}_{\mathrm{s}}}{\widetilde{T}_{\mathrm{s}}-\widetilde{T}_{\infty}}\right) \chi .
$$

In the above, $\varepsilon$ is the appropriate small parameter for expansion, and $\chi$ and $\theta$ are the inner variables.

With (52) and the coupling functions from (29) to (32), the inner species distributions are given by

$$
\begin{aligned}
\left(\widetilde{Y}_{\mathrm{O}}\right)_{\text {in }}= & \tilde{Y}_{\mathrm{O}, \mathrm{s}}+\varepsilon \widetilde{T}_{\mathrm{s}} \lambda(\chi-\theta) \\
\left(\widetilde{Y}_{\mathrm{F}}\right)_{\text {in }}= & \left(\frac{2 \delta \beta-\widetilde{Y}_{\mathrm{O}, \infty}}{1+\beta}\right)+\widetilde{Y}_{\mathrm{O}, \mathrm{s}} \\
& +\varepsilon\left(\frac{\widetilde{T}_{\mathrm{s}}}{\widetilde{T}_{\mathrm{s}}-\widetilde{T}_{\infty}}\right)\left(\frac{\widetilde{Y}_{\mathrm{O}, \infty}-2 \delta \beta}{1+\beta} \chi-\widetilde{Y}_{\mathrm{O}, \infty} \theta\right)
\end{aligned}
$$

Thus, through evaluation of the parameter $\gamma$, expressed as

$$
\begin{aligned}
\gamma \equiv\left(\frac{d \widetilde{T}}{d \xi}\right)_{s} & =\left[\frac{d \chi}{d \xi} \frac{d(\widetilde{T})_{\text {in }}}{d \chi}\right]_{s} \\
& =-\left(\widetilde{T}_{s}-\widetilde{T}_{\infty}\right)+\widetilde{Y}_{\mathrm{O}, \infty}\left(\frac{d \theta}{d \chi}\right)_{\mathrm{s}}+\mathrm{O}(\varepsilon),
\end{aligned}
$$

the $\mathrm{O}_{2}$ mass fraction at the surface is obtained as

$$
\tilde{Y}_{\mathrm{O}, \mathrm{s}}=\frac{\tilde{Y}_{\mathrm{O}, \infty}}{1+\beta+A_{\mathrm{s}, \mathrm{O}}\left[\beta /\left(-f_{\mathrm{s}}\right)\right]}\left\{1-\left(\frac{d \theta}{d \chi}\right)_{\mathrm{s}}\right\} .
$$

Substituting $\chi$, (52), (54), and (55) into the governing. (12), expanding, and neglecting the higher-order convection terms, we obtain

$$
\frac{d^{2} \theta}{d \chi^{2}}=-\Delta\left(\chi-\theta+\eta_{\mathrm{O}}\right)^{1 / 2} \exp (\lambda \theta-\chi),
$$

where

$$
\begin{gathered}
\Delta=D a_{\mathrm{g}} \exp \left(-\frac{\widetilde{T} a_{\mathrm{g}}}{\widetilde{T}_{\mathrm{s}}}\right)\left\{\frac{\beta}{\left(-f_{\mathrm{s}}\right)} \frac{\widetilde{T}_{\mathrm{s}}}{\widetilde{T}_{\mathrm{s}}-\widetilde{T}_{\infty}}\right\}^{2} \\
\times\left(\frac{\widetilde{T}_{\mathrm{s}}}{\widetilde{T} a_{\mathrm{g}}}\right)^{3 / 2}\left(\frac{\widetilde{T}_{\infty}}{\widetilde{T}_{\mathrm{s}}}\right)^{1 / 2} \frac{\widetilde{Y}_{\mathrm{F}, \mathrm{s}}}{\left(\lambda \widetilde{T}_{\mathrm{s}}\right)^{1 / 2}}, \\
\eta_{\mathrm{O}}=\frac{\widetilde{Y}_{\mathrm{O}, \mathrm{s}}}{\varepsilon \widetilde{T}_{\mathrm{s}} \lambda} .
\end{gathered}
$$


It may be noted that the situation of $Y_{\mathrm{F}, \mathrm{s}}=\mathrm{O}(\varepsilon)$ is not considered here because it corresponds to very weak carbon combustion, such as in low $\mathrm{O}_{2}$ concentration or at low surface temperature.

Evaluating the inner temperature at the surface of constant $T_{\mathrm{s}}$, one boundary condition for (58) is

$$
\theta(0)=0 \text {. }
$$

This boundary condition is a reasonable one from the viewpoint of gas-phase quasi-steadiness in that its surface temperature changes at rates much slower than that of the gas phase, since solid phase has great thermal inertia.

For the outer, nonreactive region, if we write

$$
(\widetilde{T})_{\text {out }}=\widetilde{T}_{\mathrm{s}}+\left(\widetilde{T}_{\infty}-\widetilde{T}_{\mathrm{s}}\right) \xi+\varepsilon \widetilde{T}_{\mathrm{s}} \Theta(\xi)+\mathrm{O}\left(\varepsilon^{2}\right),
$$

we see from (12) that $\Theta$ is governed by $L(\Theta)=0$ with the boundary condition that $\Theta(\infty)=0$. Then, the solution is $\Theta(\xi)=-C_{\mathrm{I}}(1-\xi)$, where $C_{\mathrm{I}}$ is a constant to be determined through matching.

By matching the inner and outer temperatures presented in (52) and (62), respectively, we have

$$
\lambda \theta(\infty)=-C_{\mathrm{I}}, \quad\left(\frac{d \theta}{d \chi}\right)_{\infty}=0,
$$

the latter of which provides the additional boundary condition to solve (58), while the former allows the determination of $C_{\mathrm{I}}$.

Thus, the problem is reduced to solving the single governing equation (58), subject to the boundary conditions (61) and (63). The key parameters are $\Delta, \lambda$, and $\eta_{\mathrm{O}}$. Before solving (58) numerically, it should be noted that there exists a general expression for the ignition criterion as

$$
\begin{aligned}
2 \Delta_{\mathrm{I}} \lambda=( & \sqrt{\eta_{\mathrm{O}}}+\sqrt{\frac{\pi / \lambda}{2}} e^{\lambda \eta_{\mathrm{O}}} \\
& \left.\times\left\{\operatorname{erfc}\left(\lambda \eta_{\mathrm{O}}\right)+(\lambda-1) \int_{\chi_{\mathrm{I}}}^{\infty} e^{(\lambda-1) \chi} \operatorname{erfc}(z) d \chi\right\}\right)^{-1},
\end{aligned}
$$$$
\operatorname{erfc}(z)=\frac{2}{\sqrt{\pi}} \exp \int_{z}^{\infty}\left(-t^{2}\right) d t
$$

corresponding to the critical condition for the vanishment of solutions at

$$
\left(\frac{d \theta}{d \chi}\right)_{s}=\frac{1}{\lambda} \quad \text { or } \quad\left(\frac{d(\widetilde{T})_{\text {in }}}{d \xi}\right)_{s}=0,
$$

which implies that the heat transferred from the surface to the gas phase ceases at the ignition point. Note also that (64) further yields analytical solutions for some special cases, such as

$$
\text { at } \begin{aligned}
\lambda= & 1: 2 \Delta_{\mathrm{I}}=\frac{1}{\sqrt{\eta_{\mathrm{O}}}+(\sqrt{\pi} / 2) e^{\eta_{\mathrm{O}}} \operatorname{erfc}\left(\lambda \eta_{\mathrm{O}}\right)}, \\
& \quad \text { as } \eta_{\mathrm{O}} \longrightarrow \infty: \quad 2 \Delta_{\mathrm{I}} \lambda=\frac{1}{\sqrt{\eta_{\mathrm{O}}}},
\end{aligned}
$$

the latter of which agrees with the result of Matalon [49].
In numerically solving (58), by plotting $\theta(\infty)$ versus $\Delta$ for a given set of $\lambda$ and $\eta_{\mathrm{O}}$, the lower ignition branch of the $S$ curve can first be obtained. The values of $\Delta$, corresponding to the vertical tangents to these curves, are then obtained as the reduced ignition Damköhler number $\Delta_{\mathrm{I}}$. After that, a universal curve of $\left(2 \Delta_{\mathrm{I}} \lambda\right)$ versus $(1 / \lambda)$ is obtained with $\eta_{\mathrm{O}}$ taken as a parameter. Recognizing that $(1 / \lambda)$ is usually less than about 0.5 for practical systems and using (64) and (67), we can fairly represent $\left(2 \Delta_{\mathrm{I}} \lambda\right)$ as [32]

$$
\begin{aligned}
2 \Delta_{\mathrm{I}} \lambda=\left(\sqrt{\eta_{\mathrm{O}}}+\frac{\sqrt{\pi}}{2}\left[e^{\eta_{\mathrm{O}}}\right.\right. & \operatorname{erfc}\left(\sqrt{\eta_{\mathrm{O}}}\right) \\
& \left.\left.+\left\{\frac{1}{F(\lambda)}-1\right\} \exp \left(-\frac{\sqrt{\eta_{\mathrm{O}}}}{2}\right)\right]\right)^{-1},
\end{aligned}
$$

where

$$
F(\lambda)=0.56+\frac{0.21}{\lambda}-\frac{0.12}{\lambda^{2}}+\frac{0.35}{\lambda^{3}} .
$$

Note that for large values of $(1 / \lambda),(68)$ is still moderately accurate. Thus, for a given set of $\lambda$ and $\eta_{\mathrm{O}}$, an ignition Damköhler number can be determined by substituting the values of $\Delta_{\mathrm{I}}$, obtained from (68), into (59).

It may be informative to note that for some weakly burning situations, in which $\mathrm{O}_{2}$ concentrations in the reaction zone and at the carbon surface are $\mathrm{O}(1)$, a monotonic transition from the nearly frozen to the partial-burning behaviors is reported [31], instead of an abrupt, turning-point behavior, with increasing gas-phase Damköhler number. However, this could be a highly limiting behavior; that is, in order for the gas-phase reaction to be sufficiently efficient, and the ignition to be a reasonably plausible event, enough $\mathrm{CO}$ would have to be generated at the surface, which further requires a sufficiently fast surface $\mathrm{C}-\mathrm{O}_{2}$ reaction and hence the diminishment of the surface $\mathrm{O}_{2}$ concentration from $\mathrm{O}(\mathrm{l})$. For these situations, the turning-point behavior can be a more appropriate indication for the ignition.

4.4. Dominant Parameters for the Ignition of CO Flame. Figure 3(a) shows the ignition surface-temperature $T_{\text {s,ig }}$ [34], as a function of the velocity gradient. The velocity gradient has been chosen for the abscissa, as originally proposed by Tsuji and Yamaoka [51] for the diffusion flame, and its appropriateness has been examined by Makino and Law [32] for the two-dimensional flow configuration, by varying both the freestream velocity and graphite rod diameter that can exert influences in determining velocity gradient. It is seen that the ignition surface-temperature $T_{\text {s,ig }}$ increases with increasing velocity gradient and thereby decreasing residence time. The high surface temperature, as well as the high temperature in the reaction zone, causes the high ejection rate of $\mathrm{CO}$ through the surface $\mathrm{C}-\mathrm{O}_{2}$ reaction. These enhancements facilitate the $\mathrm{CO}$ flame, by reducing the characteristic chemical reaction time, and hence compensating a decrease in the characteristic residence time.

A solid curve in Figure 3(a) is the ignition surfacetemperature for the prescribed conditions, predicted by 


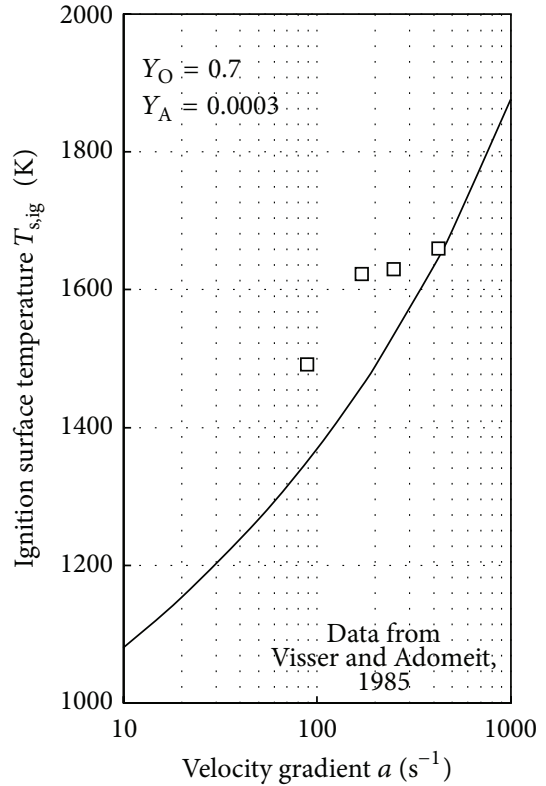

(a)

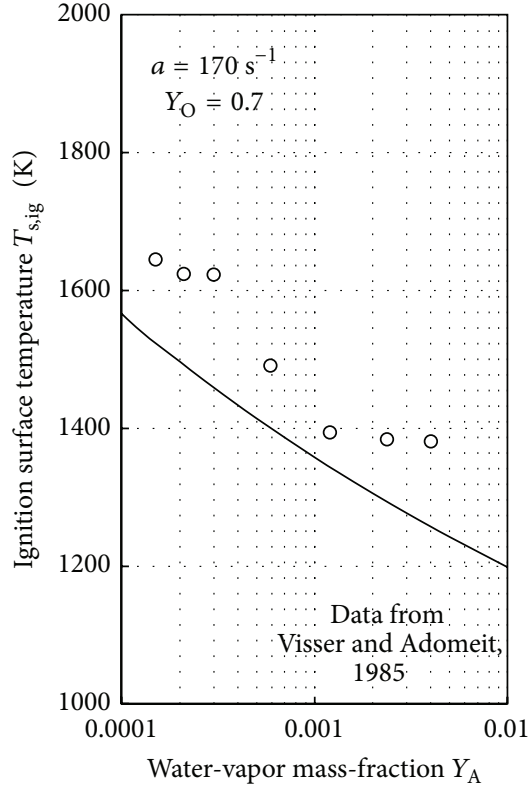

(b)

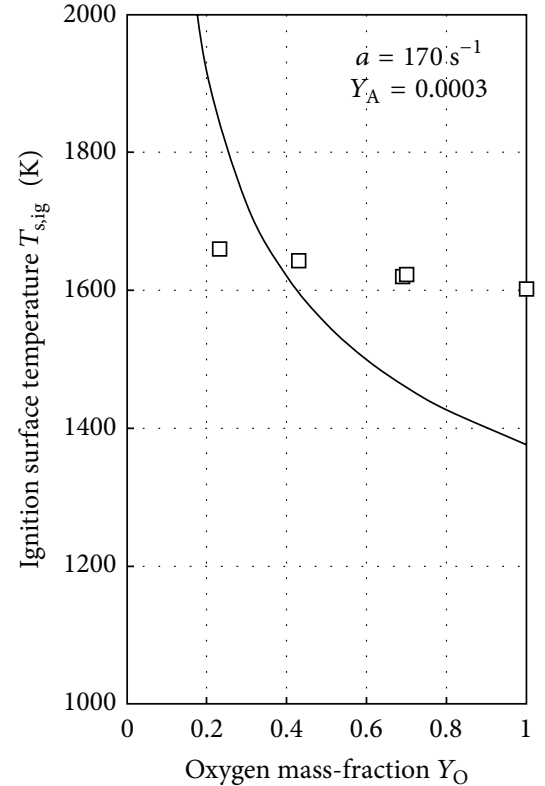

(c)

FIGURE 3: Surface temperature at the establishment of $\mathrm{CO}$ flame, as a function of (a) the stagnation velocity gradient; $(\mathrm{b})$ the $\mathrm{H}_{2} \mathrm{O}$ massfraction in the freestream; (c) the $\mathrm{O}_{2}$ mass-fraction. Data points are experimental in [34]; curves are calculated from the theory in [32], with gas-phase kinetic parameters [42].

the ignition criterion [32] presented in the previous section, with using kinetic parameters [42] to be mentioned in the next section. The density $\rho_{\infty}$ of the oxidizing gas in the freestream is estimated at $T_{\infty}=323 \mathrm{~K}$. It is seen that fair agreement is demonstrated, suggesting that the present ignition criterion has captured the essential feature of the ignition of CO-flame over the burning carbon.

Figure 3(b) shows the ignition surface-temperature $T_{\mathrm{s}, \mathrm{ig}}$, as a function of the $\mathrm{H}_{2} \mathrm{O}$ mass fraction in the freestream. It is seen that the ignition surface-temperature decreases with increasing $\mathrm{H}_{2} \mathrm{O}$ mass fraction, because the $\mathrm{CO}-\mathrm{O}_{2}$ reaction is facilitated with increasing concentration of $\mathrm{H}_{2} \mathrm{O}$, as is well known, and so-called as the "catalytic effect" of water-vapor on the CO-oxidation rate. Figure 3(c) shows the ignition surface temperature, as a function of the $\mathrm{O}_{2}$ mass fraction in the freestream. It is also seen that the ignition surfacetemperature decreases with increasing $\mathrm{O}_{2}$ mass fraction. In this case the $\mathrm{CO}-\mathrm{O}_{2}$ reaction is facilitated with increasing concentrations of $\mathrm{O}_{2}$, as well as $\mathrm{CO}$, because more $\mathrm{CO}$ is now produced through the surface $\mathrm{C}-\mathrm{O}_{2}$ reaction. Although agreement is not so good, as far as the approximate magnitude is concerned, both the experimental and predicted results exhibit a decreasing trend with increasing $\mathrm{O}_{2}$ mass fraction.

\subsection{Kinetic Parameters for the Global Gas-Phase Reaction.} Estimation of gas-phase kinetic parameters has already been conducted [32, 42], with experimental data for the ignition surface temperature in the two-dimensional stagnation flow and the ignition criterion for the $\mathrm{CO}$ flame over the burning carbon. Here, reaction orders are a priori assumed to be $n_{\mathrm{F}}=$ 1 and $n_{\mathrm{O}}=0.5$, which are the same as those of the global rate expression, presented by Howard et al. [36]. It is also assumed that the frequency factor $B_{\mathrm{g}}$ is proportional to the half order of $\mathrm{H}_{2} \mathrm{O}$ concentration; that is,

$$
B_{\mathrm{g}}=B_{\mathrm{g}}^{*}\left(\rho Y_{\mathrm{A}} / W_{\mathrm{A}}\right)^{1 / 2}\left[\left(\mathrm{~mol} / \mathrm{m}^{3}\right)^{1 / 2} \cdot \mathrm{s}\right]^{-1},
$$

where the subscript $\mathrm{A}$ designates water vapor. The $\mathrm{H}_{2} \mathrm{O}$ mass fraction at the surface is estimated with $Y_{\mathrm{A}, \mathrm{s}}=Y_{\mathrm{A}, \infty} /(1+\beta)$, with water vapor taken as an inert because it acts as a kind of catalyst for the gas-phase $\mathrm{CO}-\mathrm{O}_{2}$ reaction, and hence its profile is not anticipated to be influenced. Thus, for a given set of $\lambda$ and $\eta_{\mathrm{O}}$, an ignition Damköhler number can be determined by substituting $\Delta_{\mathrm{I}}$ in (68) into (59).

Figure 4 shows the Arrhenius plot of the global gasphase reactivity [42], obtained as the results of the ignition surface temperature. In data processing, data in a series of experiments $[32,42]$ have been used, by use of kinetic parameters for the surface $\mathrm{C}-\mathrm{O}_{2}$ reaction. With iteration in terms of the activation temperature, required for determining $\Delta_{\mathrm{I}}$ with respect to $\eta_{\mathrm{O}}, E_{\mathrm{g}}=113 \mathrm{~kJ} / \mathrm{mol}$ is obtained with

$$
B_{\mathrm{g}}^{*}=9.1 \times 10^{6}\left[\left(\mathrm{~mol} / \mathrm{m}^{3}\right) \cdot \mathrm{s}\right]^{-1} .
$$

This activation energy is within the range of the global CO- $\mathrm{O}_{2}$ reaction (cf. Table II in [36]).

It is noted that $B_{\mathrm{g}}^{*}$ obtained is one order of magnitude lower than that of Howard et al. [36], which is reported to be

$$
B_{\mathrm{g}}^{*}=1.3 \times 10^{8}\left[\left(\mathrm{~mol} / \mathrm{m}^{3}\right) \cdot \mathrm{s}\right]^{-1},
$$

because the present value is that prior to the appearance of $\mathrm{CO}$ flame and is to be low, compared to that of the "strong" 


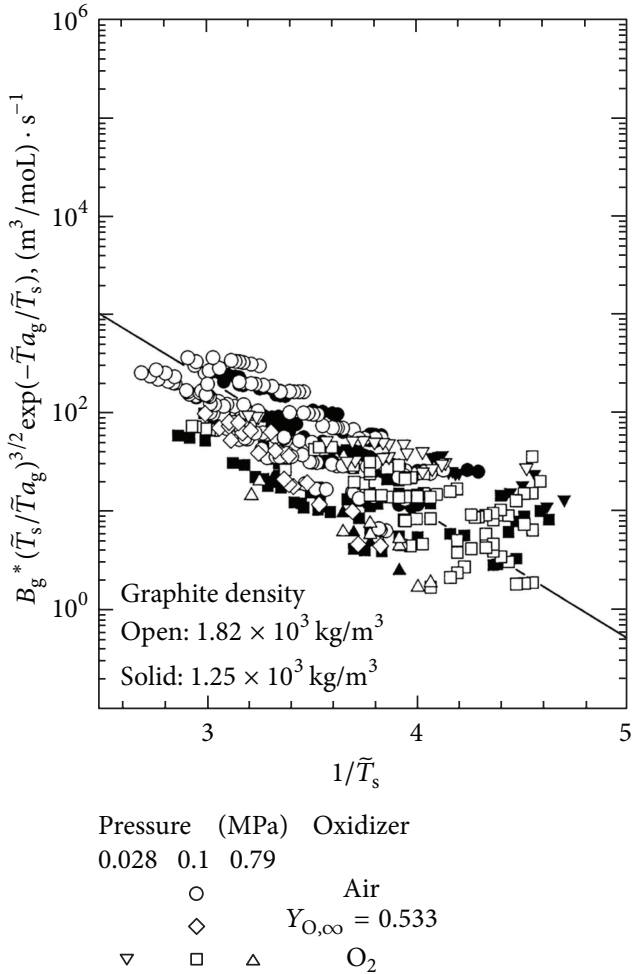

FIGURE 4: Arrhenius plot of the global gas-phase reaction [42], obtained from the experimental results of the ignition surfacetemperature in two-dimensional stagnation flows with various pressures, $\mathrm{O}_{2}$ and $\mathrm{H}_{2} \mathrm{O}$ concentrations, and velocity gradients.

CO oxidation in the literature. As for the "weak" CO oxidation, Sobolev [52] reported

$$
B_{\mathrm{g}}^{*}=3.0 \times 10^{6}\left[\left(\mathrm{~mol} / \mathrm{m}^{3}\right) \cdot \mathrm{s}\right]^{-1},
$$

by examining data of Chukhanov $[53,54]$ who studied the initiation of $\mathrm{CO}$ oxidation, accompanied by the carbon combustion. We see that the value reported [52] exhibits a lower bound of the experimental results shown in Figure 4.

It is also confirmed in Figure 4 that there exists no remarkable effects of $\mathrm{O}_{2}$ and/or $\mathrm{H}_{2} \mathrm{O}$ concentrations in the oxidizer; thereby, the assumption for the reaction orders is shown to be appropriate within the present experimental conditions. The choice of reaction orders, however, requires a further comment because another reaction order for $\mathrm{O}_{2}$ concentration, 0.25 in place of 0.5 , is recommended in the literature. Relevant to this, an attempt [42] has further been conducted to compare the experimental data with another ignition criterion, obtained through a similar ignition analysis with this reaction order. However, its result was unfavorable, presenting a much poorer correlation between them.

\section{Experimental Comparisons}

5.1. Other Sources for the Combustion Rate. Experimental comparisons have already been conducted in Figure 1 and a fair degree of agreement has been demonstrated, as far as the trend and approximate magnitude are concerned. Here, further experimental comparisons are to be made for results of Golovina and Khaustovich [55], with keeping both the gas-phase and surface kinetic parameters fixed. Figure 5(a) compares predicted results with experimental data in airflow of $120 \mathrm{~s}^{-1}$ at an atmospheric pressure, the freestream velocity $V_{\infty}=0.6 \mathrm{~m} / \mathrm{s}$, and the sphere diameter $d=15 \mathrm{~mm}$, made of electrode carbon. The ignition surface temperature is estimated to be $T_{\text {s,ig }} \approx 1479 \mathrm{~K}$, obtained by assuming the $\mathrm{H}_{2} \mathrm{O}$ mass fraction to be 0.003 , the dew point of which is $271 \mathrm{~K}$ $\left(-2^{\circ} \mathrm{C}\right)$. Values of thermophysical properties are those for air at $T_{\infty}=320 \mathrm{~K}$, which yields $\rho_{\infty} \mu_{\infty}=2.12 \times 10^{-5} \mathrm{~kg}^{2} /\left(\mathrm{m}^{4} \cdot \mathrm{s}\right)$ and $\mu_{\infty} / \rho_{\infty}=1.78 \times 10^{-5} \mathrm{~m}^{2} / \mathrm{s}$, used in the previous work $[28,42]$. We see from Figure 5(a) that up to the ignition surface temperature $T_{\text {s,ig }}$ the combustion proceeds under the "weak" or negligible CO oxidation, and that the "strong" CO oxidation prevails at temperatures higher than the ignition surface temperature. Unfortunately, because of the lack of the experimental data, the abrupt change in the combustion rate does not appear clearly, although the general behavior seems to be similar to that in Figures 1(a) and 1(b).

Figure 5(b) compares predicted results with experimental data in $\mathrm{CO}_{2}$ flow of $120 \mathrm{~s}^{-1}$, with the $\mathrm{CO}_{2}$ mass fraction of 0.5 . A fair degree of agreement is demonstrated in the trend and approximate magnitude, except for the temperature range from $2000 \mathrm{~K}$ to $2500 \mathrm{~K}$. The discrepancy in this temperature range has been attributed to the dust separation from the surface, the density change of carbon, and so forth $[33,55]$, which have not been taken into account in the present formulation described in Section 2.

Figure 5(c) compares predicted results with experimental data in $\mathrm{H}_{2} \mathrm{O}$ flow of $120 \mathrm{~s}^{-1}$, with the $\mathrm{H}_{2} \mathrm{O}$ mass fraction of 0.5 . The solid curve is predicted with the surface kinetic parameters for the $\mathrm{C}-\mathrm{H}_{2} \mathrm{O}$ reaction as $B_{\mathrm{s}, \mathrm{A}}=2.0 \times 10^{7} \mathrm{~m} / \mathrm{s}$ and $E_{\mathrm{s}, \mathrm{A}} / R=3.3 \times 10^{4} \mathrm{~K}\left(E_{\mathrm{s}, \mathrm{A}}=271 \mathrm{~kJ} / \mathrm{mol}\right)$, evaluated and used in the previous work [56]. Again, fair agreement is demonstrated.

5.2. Approximate, Explicit Expressions for the Combustion Rate. In general, in order to calculate the combustion rate, temperature profiles in the gas phase must be obtained by numerically solving the energy conservation equation for finite gas-phase reaction kinetics. However, if we note that carbon combustion proceeds with nearly frozen gas-phase chemistry until the establishment of the CO flame $[42,45,46]$ and that the combustion is expected to proceed under nearly infinite gas-phase kinetics once the CO-flame is established, analytically-obtained combustion rates [23, 27], presented in Section 3, are still useful and valuable for practical utility.

However, it should also be noted that the combustionrate expressions thus obtained are implicit, so that further numerical calculations are required by taking account of the relation, $\beta \equiv\left(-f_{s}\right) /\left(\xi^{\prime}\right)_{s}$, which is a function of the streamfunction $f$. Since this procedure is slightly complicated and cannot be used easily in practical situations, explicit expressions are anxiously required, in order to make these results more useful. 


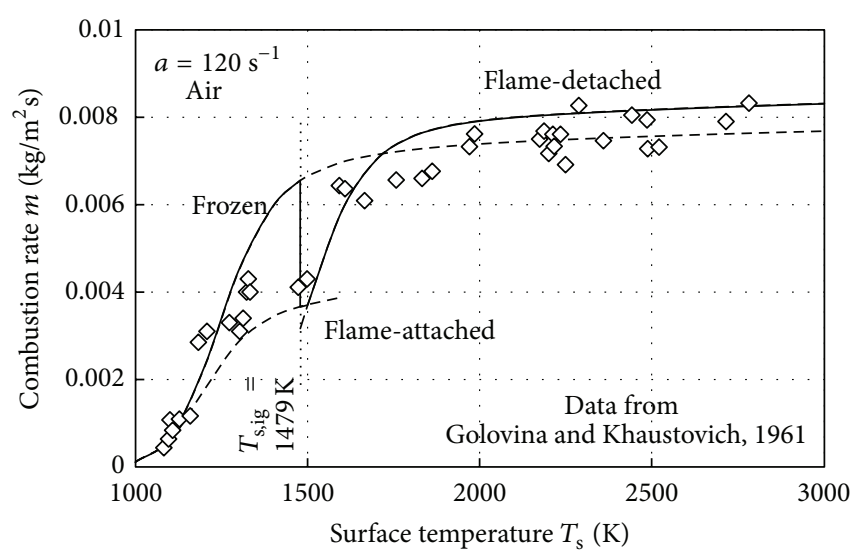

(a)

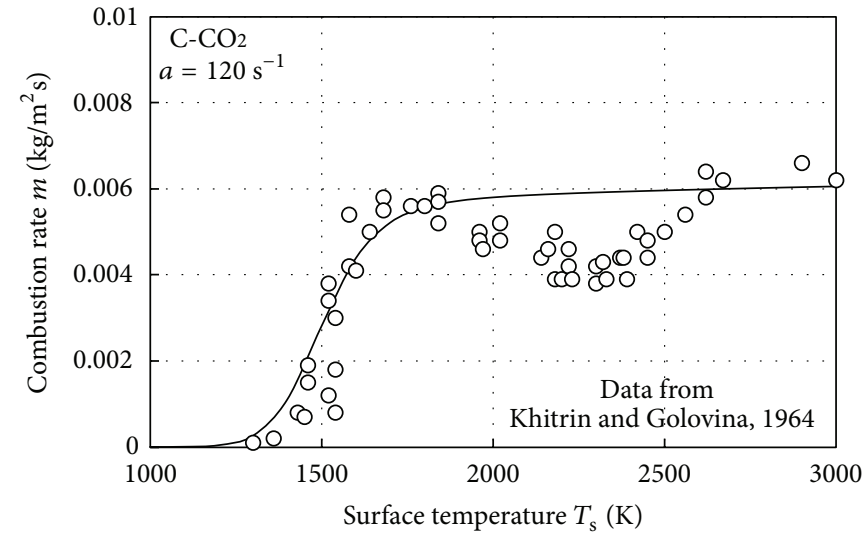

(b)

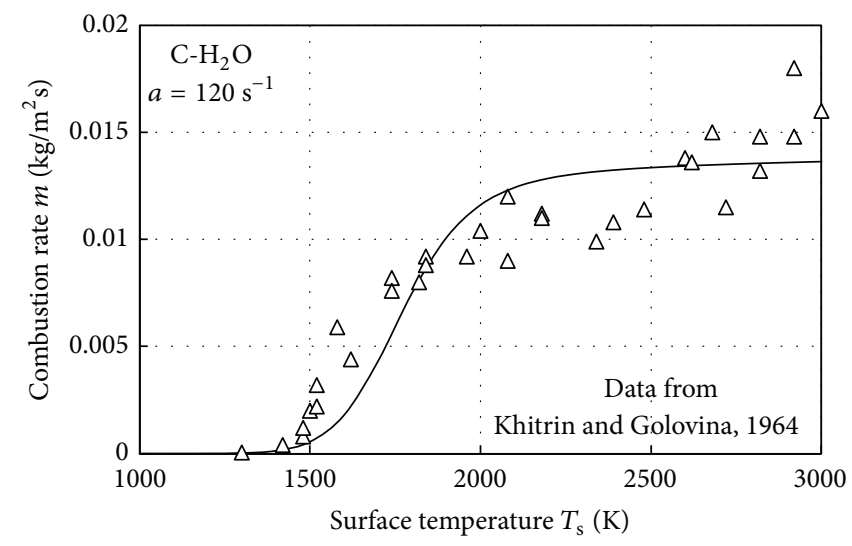

(c)

FIGURE 5: Experimental comparisons for the combustion rate under an atmospheric pressure: (a) in airflow; (b) in $\mathrm{CO}_{2}$-flow with $\mathrm{CO}_{2}$ mass fraction of 0.5 ; (c) in $\mathrm{H}_{2} \mathrm{O}$-flow with $\mathrm{H}_{2} \mathrm{O}$ mass fraction of 0.5 . Data points are experimental $[33,55]$ and curves are calculated from the theory.

In order to elucidate the relation between $\left(-f_{\mathrm{s}}\right)$ and $\beta$, dependence of $\left(\xi^{\prime}\right)_{\text {s }}$ on streamfunction $f$ is first to be examined, by introducing a simplified profile of $f$ as

$$
f= \begin{cases}f_{\mathrm{s}} & \left(0 \leq \eta \leq \eta_{*}\right) \\ b \eta+c & \left(\eta_{*} \leq \eta \leq \eta_{* *}\right) \\ \eta+d & \left(\eta \geq \eta_{* *}\right)\end{cases}
$$

before conducting an integration. Here, $b, c$, and $d$ are constants, $f\left(\eta_{*}\right)=f_{\mathrm{s}}$, and $f\left(\eta_{* *}\right)=f_{o}$.

Recalling the definitions of $\beta$ and $\left(\xi^{\prime}\right)_{s}$, and making use of a relation, $\left(-f_{\mathrm{s}}\right) \ll 1$, as is the case for most solid combustion, we have the following approximate relation [28]:

$$
1+\beta \approx \exp \left[K\left(-f_{\mathrm{s}}\right)\right] \quad \text { or } \quad\left(-f_{\mathrm{s}}\right) \approx \frac{\ln (1+\beta)}{K},
$$

where

$$
\begin{aligned}
K=\eta_{*}+\sqrt{\frac{\pi}{2}}[ & \left\{\exp \left(\frac{(b-1) f_{o}^{2}}{2 b}\right)-1\right\} \operatorname{erfc}\left(\frac{f_{o}}{\sqrt{2}}\right) \\
& \left.+\frac{1}{\sqrt{b}} \operatorname{erf}\left(\frac{f_{o}}{\sqrt{2 b}}\right)-\operatorname{erf}\left(\frac{f_{o}}{\sqrt{2}}\right)\right]+\sqrt{\frac{\pi}{2}} .
\end{aligned}
$$

Equation (75) shows that the combustion rate $\left(-f_{\mathrm{s}}\right)$ can be expressed by the transfer number $\beta$ in terms of the logarithmic term, $\ln (1+\beta)$. Note that the first and second terms in (76) are one order of magnitude smaller than the third term $(\pi / 2)^{1 / 2}$.

In order to obtain the specific form of the transfer number $\beta$, a two-term expansion of the exponential function is expected to be sufficient because $\left(-f_{\mathrm{s}}\right) \ll 1$, so that use has been made of the following relation $[27,28]$;

$$
\frac{\beta}{1+\beta}=1-\exp \left[-K\left(-f_{\mathrm{s}}\right)\right] \approx K\left(-f_{\mathrm{s}}\right) .
$$

By virtue of this relation, (39), (42), and (49) yield the following approximate expressions for the transfer number [28], respectively.

Frozen mode:

$$
\begin{aligned}
\beta \approx & \left(\frac{K A_{\mathrm{s}, \mathrm{O}}}{1+K A_{\mathrm{s}, \mathrm{O}}}\right)\left(\frac{2 W_{\mathrm{C}}}{W_{\mathrm{O}}} Y_{\mathrm{O}, \infty}\right) \\
& +\left(\frac{K A_{\mathrm{s}, \mathrm{P}}}{1+K A_{\mathrm{s}, \mathrm{P}}}\right)\left(\frac{W_{\mathrm{C}}}{W_{\mathrm{P}}} Y_{\mathrm{P}, \infty}\right) .
\end{aligned}
$$


Flame-detached mode:

$$
\beta \approx\left(\frac{K A_{\mathrm{s}, \mathrm{P}}}{1+K A_{\mathrm{s}, \mathrm{P}}}\right)\left(\frac{2 W_{\mathrm{C}}}{W_{\mathrm{O}}} Y_{\mathrm{O}, \infty}+\frac{W_{\mathrm{C}}}{W_{\mathrm{P}}} Y_{\mathrm{P}, \infty}\right) .
$$

Flame-attached mode:

$$
\begin{aligned}
\beta \approx & \left(\frac{K A_{\mathrm{s}, \mathrm{O}}}{1+2 K A_{\mathrm{s}, \mathrm{O}}-K A_{\mathrm{s}, \mathrm{P}}}\right)\left(\frac{2 W_{\mathrm{C}}}{W_{\mathrm{O}}} Y_{\mathrm{O}, \infty}\right) \\
& +\left(\frac{K A_{\mathrm{s}, \mathrm{P}}}{1+2 K A_{\mathrm{s}, \mathrm{O}}-K A_{\mathrm{s}, \mathrm{P}}}\right)\left(\frac{W_{\mathrm{C}}}{W_{\mathrm{P}}} Y_{\mathrm{P}, \infty}\right) .
\end{aligned}
$$

Although these are approximate, the transfer number can be expressed explicitly, in terms of the reduced surface Damköhler numbers, $A_{\mathrm{s}, \mathrm{O}}$ and $A_{\mathrm{s}, \mathrm{P}}$, and $\mathrm{O}_{2}$ and $\mathrm{CO}_{2}$ concentrations in the freestream.

In addition, we have

$$
K A_{\mathrm{s}, i}=k_{\mathrm{s}, i} \frac{K}{\sqrt{2^{j} a\left(\mu_{\infty} / \rho_{\infty}\right)}},
$$

where $k_{\mathrm{s}, i}$ is the specific reaction rate constant for the surface reaction, expressed as

$$
k_{\mathrm{s}, i} \equiv B_{\mathrm{s}, i}\left(\frac{T_{\infty}}{T_{\mathrm{s}}}\right) \exp \left(-\frac{T a_{\mathrm{s}, i}}{T_{\mathrm{s}}}\right) \quad(i=\mathrm{O}, \mathrm{P}) .
$$

Note that the factor, $K /\left[2^{j} a\left(\mu_{\infty} / \rho_{\infty}\right)\right]^{1 / 2}$, in (81) also appears in the combustion rate defined in (28), by use of the relation in (75), as

$$
\dot{m} \approx \rho_{\infty} \frac{\sqrt{2^{j} a\left(\mu_{\infty} / \rho_{\infty}\right)}}{K} \ln (1+\beta) .
$$

5.3. Correction Factor $K$ and Mass-Transfer Coefficient. In order to elucidate the physical meaning of the factor,

$$
\frac{K}{\left[2^{j} a\left(\mu_{\infty} / \rho_{\infty}\right)\right]^{1 / 2}}
$$

let us consider the situation that $\beta \ll 1$, with the frozen mode combustion taken as an example. Then, (83) leads to the following result:

$$
\begin{aligned}
\dot{m} \approx & \frac{1}{1 / k_{\mathrm{s}, \mathrm{O}}+K / \sqrt{2^{j} a\left(\mu_{\infty} / \rho_{\infty}\right)}} \rho_{\infty}\left(\frac{2 W_{\mathrm{C}}}{W_{\mathrm{O}}} Y_{\mathrm{O}, \infty}\right) \\
& +\frac{1}{1 / k_{\mathrm{s}, \mathrm{P}}+K / \sqrt{2^{j} a\left(\mu_{\infty} / \rho_{\infty}\right)}} \rho_{\infty}\left(\frac{W_{\mathrm{C}}}{W_{\mathrm{P}}} Y_{\mathrm{P}, \infty}\right) .
\end{aligned}
$$

We see that this expression is similar to the well-known expression for the combustion rate of solid,

$$
\dot{m}=\frac{1}{1 / k_{\mathrm{s}}+1 / h_{D}}\left(\rho Y_{\mathrm{O}}\right)_{\infty}
$$

for the first-order kinetics [57-60]. Here, $h_{D}$ is the overall convective mass-transfer coefficient. It is seen that the factor, $\left[2^{j} a\left(\mu_{\infty} / \rho_{\infty}\right)\right]^{1 / 2} / K$, corresponds to the mass-transfer coefficient $h_{D}$, suggesting that the specific form of $h_{D}$ is of use in determining a form of the correction factor $K$.

Furthermore, by evaluating mass fluxes at the surface and in the gas phase, with the elemental carbon, $\left(W_{\mathrm{C}} / W_{\mathrm{F}}\right) Y_{\mathrm{F}}+$ $\left(W_{\mathrm{C}} / W_{\mathrm{P}}\right) Y_{\mathrm{P}}$, taken as the transferred substance, and by use of the coupling function in (29), we have

$$
h_{D}=\left(\frac{T_{R}}{T_{\infty}}\right)\left(\xi^{\prime}\right)_{s} \sqrt{2^{j} a\left(\mu_{\infty} / \rho_{\infty}\right)}
$$

suggesting that the correction factor $K$ depends on both $\left(\xi^{\prime}\right)_{\mathrm{s}}$ and the representative temperature $T_{R}$ in the boundary layer.

5.4. Expression of the Correction Factor $K$. In obtaining an approximate expression for the factor $K$, it seems that we can use the accomplishment in the field of heat and mass transfer. The mass-transfer coefficient is given as $[61,62]$

$$
\begin{gathered}
h_{D}=\left(\frac{T_{R}}{T_{\infty}}\right) \frac{C_{\mathrm{mt}}}{\mathrm{Sc}^{0.6}} \sqrt{a\left(\mu_{\infty} / \rho_{\infty}\right)} \\
\text { from } \frac{\mathrm{Nu}_{x}}{\sqrt{\mathrm{Re}_{x}}}=C_{\mathrm{mt}} \mathrm{Sc}^{0.4},
\end{gathered}
$$

where $C_{\mathrm{mt}}=0.763$ and 0.570 for the axisymmetric and two-dimensional stagnation flows, respectively, based on the analogy between heat and mass transfers, where

$$
\begin{gathered}
\mathrm{Nu}_{x}=\frac{h_{D} x}{D_{R}}, \quad \operatorname{Re}_{x}=\frac{\rho_{R} U x}{\mu_{R}}, \\
U=a x, \quad \mathrm{Sc}=\frac{\mu / \rho}{D} .
\end{gathered}
$$

However, this kind of expression is far from satisfaction because (88) is originally obtained for heat-transfer problems without mass transfer. In addition, this relation is obtained under an assumption that there is no density change, even though there exist temperature and/or concentration distributions in the gas phase.

Because of the simultaneous existence of temperature and concentration distributions in the carbon combustion, we are required to obtain an approximate expression for the factor $K$ in another way. In this attempt [28], $(\pi / 2)^{1 / 2}$ in the factor $K$ in (76) is kept as it is because it is $1 /\left(\xi^{\prime}\right)_{\text {s }}$ for the inviscid stagnation flow without mass ejection from the surface. The remaining part of the factor $K$ is then determined by use of numerical results $[23,42,45]$. In this determination, use has been made of a curve-fitting method, with $\left(T_{\infty} / T_{\mathrm{s}}\right)$ taken as a variable, to have a simple function.

It has turned out that we can fairly represent the combustion rate for the frozen and/or flame-attached modes in the axisymmetric stagnation flow with

$$
K=\sqrt{\frac{2}{3}\left(\frac{T_{\infty}}{T_{s}}\right)\left(1-\frac{T_{\infty}}{2 T_{s}}\right)}+\sqrt{\frac{\pi}{2}},
$$

within 3\% error for $Y_{\mathrm{O}, \infty}=0.233$ [28], within $6 \%$ error for $Y_{\mathrm{O}, \infty}=0.7$ (cf. Figure 6). Examinations have been made 


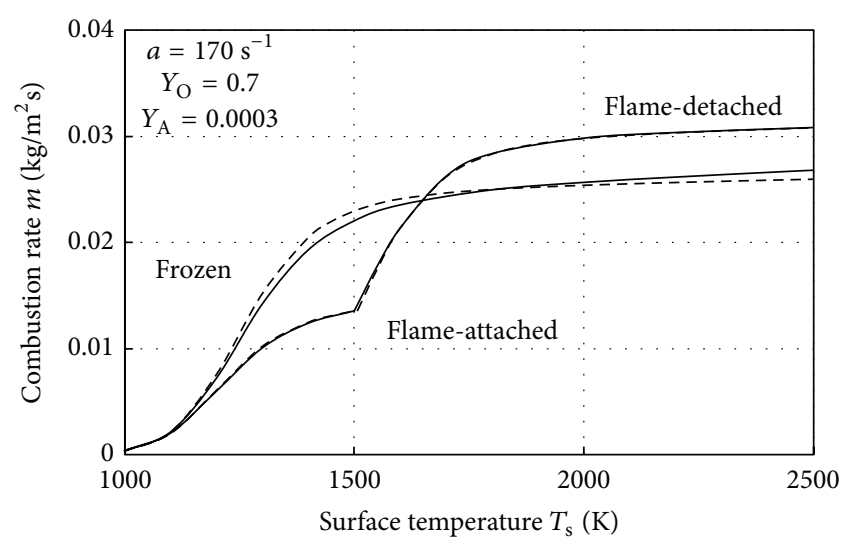

FIGURE 6: Combustion rates for the three limiting modes in the stagnation oxidizer flow as a function of the surface temperature. The solid curves are numerical results and dashed curves are those of the explicit expressions.

in the range of the surface Damköhler numbers $D a_{\mathrm{s}, \mathrm{O}}$ and $D a_{\mathrm{s}, \mathrm{P}}$ from $10^{6}$ to $10^{10}$, that of the surface temperature $T_{\mathrm{s}}$ from $1077 \mathrm{~K}$ to $2424 \mathrm{~K}$, and that of the freestream temperature $T_{\infty}$ from $323 \mathrm{~K}$ to $1239 \mathrm{~K}$. The frozen and flame-attached modes can fairly be correlated by the single equation (90) because the gas-phase temperature profiles are the same. Note that the combustion rate in high $\mathrm{O}_{2}$ concentrations violates the assumption that $\left(-f_{\mathrm{s}}\right) \ll 1$. Nonetheless, the expressions appear to provide a fair representation because these expressions vary as the natural logarithm of the transfer number.

In the flame-detached mode, not only the surface and freestream temperatures but also the oxidizer concentration that must be taken into account. It has turned out that

$$
\begin{aligned}
K= & \sqrt{\frac{2}{3}\left(\frac{T_{\infty}}{T_{s}}\right)\left(1-\frac{T_{\infty}}{2 T_{s}}\right)} \\
& -0.05\left(1+\frac{4 W_{\mathrm{C}}}{W_{\mathrm{O}}} Y_{\mathrm{O}, \infty}\right)+\sqrt{\frac{\pi}{2}}
\end{aligned}
$$

can fairly represent the combustion rate in axisymmetric stagnation flow, within $4 \%$ error when the $\mathrm{O}_{2}$ mass-fraction $Y_{\mathrm{O}, \infty}$ is 0.233 and 0.533 , although the error becomes $6 \%$ near the transition state for the flame attaches. In an oxygen flow, the error is within $6 \%$ except for the transition state, while it increases up to $15 \%$ around the state.

As for the two-dimensional stagnation flow, it has already been shown that the combustion rate in the frozen and/or flame-attached modes can fairly be represented with

$$
K=\left(\frac{T_{\infty}}{T_{s}}\right)\left(1-\frac{T_{\infty}}{2 T_{s}}\right)+\sqrt{\frac{\pi}{2}}
$$

and that in the flame-detached mode with

$$
\begin{aligned}
K= & \left(\frac{T_{\infty}}{T_{\mathrm{s}}}\right)\left(1-\frac{T_{\infty}}{2 T_{\mathrm{s}}}\right) \\
& -0.05\left(1+\frac{4 W_{\mathrm{C}}}{W_{\mathrm{O}}} Y_{\mathrm{O}, \infty}\right)+\sqrt{\frac{\pi}{2}} .
\end{aligned}
$$

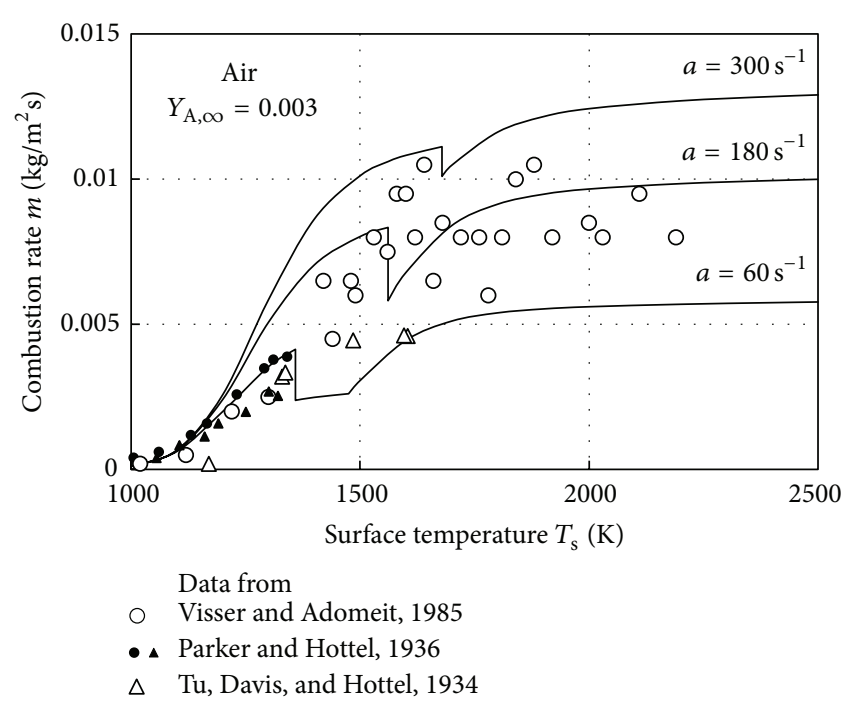

(a)

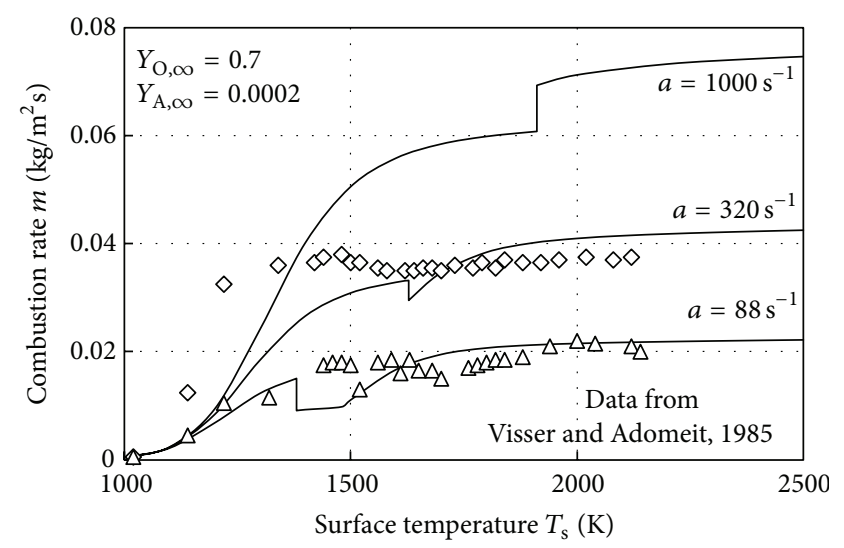

(b)

FIGURE 7: Combustion rate as a function of the surface temperature, with the velocity gradient taken as a parameter: (a) in airflow with the $\mathrm{H}_{2} \mathrm{O}$ mass-fraction $Y_{\mathrm{A}, \infty}=0.003$; (b) in oxidizing-flow with $Y_{\mathrm{O}, \infty}=0.7$ and $Y_{\mathrm{A}, \infty}=0.0002$. Data points are experimental results $[34,59,63]$ in airflow and those [34] in oxidizing flow; curves are calculated by use of the explicit combustion-rate expressions.

The errors in these modes are nearly the same as those for the axisymmetric case, respectively. The difference in expressions in (90) and (92), and that in (91) and (93) can be attributed to the difference in the flow configurations.

5.5. Combustion Rates at Various Velocity Gradients. In order to verify the validity of the explicit combustion-rate expressions, further experimental comparisons have been conducted. Kinetic parameters and values of thermophysical properties are those evaluated and used in the previous sections. Experimental data used are those in the literature $[34,59,63]$.

Figure 7(a) shows the combustion rate in airflow as a function of the surface temperature, with the velocity gradient taken as a parameter. The $\mathrm{H}_{2} \mathrm{O}$ mass fraction in airflow is set to be 0.003 , in the same manner as that in Figure 5(a). 
When the velocity gradient is $60 \mathrm{~s}^{-1}$, it is predicted that with increasing surface temperature, the combustion rate first increases, then decreases abruptly, and again increases, as shown in Figure 1(b). As the velocity gradient is increased, even up to $300 \mathrm{~s}^{-1}$, the trend is still the same although the combustion rate becomes high, due to an enhanced oxidizer supply.

Note that use has also been made of the combustionrate expressions. Up to the ignition surface temperature, a reasonable prediction can be made by (75), with the transfer number $\beta$ for the frozen mode in (78) and the correction factor $K$ in (90), for axisymmetric case. When the surface temperature is higher than the ignition surface temperature, (75) with $\beta$ for the flame-detached mode in (79) and $K$ in (91) can fairly represent the experimental results, except for the temperatures near the ignition surface temperature at low velocity gradients, say, $60 \mathrm{~s}^{-1}$ in Figure 7(a). In this temperature range, we can use (75) with $\beta$ for the flameattached mode in (80) and $K$ in (90) although accuracy of this prediction is not so high, compared to the others. This is attributed to the fact that we cannot assume infinitely fast gas-phase reaction rates because the combustion situation is that just after the establishment of CO flame.

Data points are experimental; Tu et al. [59] made an experiment under a condition of $a=60 \mathrm{~s}^{-1}$, using a spherical specimen (brush carbon; $d=25 \mathrm{~mm}$ ) in airflow $(0.5 \mathrm{~m} / \mathrm{s})$; Parker and Hottel [63] did an experiment under conditions of $a=60 \mathrm{~s}^{-1}(\mathbf{\Lambda})$ and $180 \mathrm{~s}^{-1}(\bullet)$, using a hemispherical specimen (brush carbon; $d=25 \mathrm{~mm}$ ) in airflow (up to $1.5 \mathrm{~m} / \mathrm{s}$ ); Visser and Adomeit [34] did an experiment under conditions of $a=170 \mathrm{~s}^{-1}$, using a hemispherical specimen (artificial graphite; $d=15 \mathrm{~mm}$ ) in oxidizer flow $(0.85 \mathrm{~m} / \mathrm{s}$ ) with $\mathrm{O}_{2}$ mass-fraction $Y_{\mathrm{O}, \infty}=0.18$. Experimental data of Visser and Adomeit [34] have been used because no other results in airflow can be found for the axisymmetric case. Nonetheless, it can even be justified if we take account of a possibility that the ambient air has been entrained by the oxidizer flow, thereby the oxygen concentration is enriched. The scatter of the combustion rate in the temperature range from $1500 \mathrm{~K}$ to $1800 \mathrm{~K}$ can be attributed to a fluctuation of water-vapor concentration in the oxidizing flow, which can exert influences on the appearance of $\mathrm{CO}$ flame.

Figure $7(\mathrm{~b})$ is the similar plot of the combustion rate in oxidizer flow with the $\mathrm{O}_{2}$ mass fraction $\mathrm{Y}_{\mathrm{O}, \infty}=0.7$. The $\mathrm{H}_{2} \mathrm{O}$ mass fraction in oxidizer flow is set to be 0.0002 , in accordance with the experimental condition [34]. The same trend as that observed in Figure 7(a) can be shown, even in the oxygen-enriched condition. However, a further increase in the velocity gradient, under which no experiments have ever been reported in the axisymmetric stagnation flow, can change the trend. When the velocity gradient is $1000 \mathrm{~s}^{-1}$, which is even higher than that ever used in the previous experiment [37], the combustion rate first increases, then reaches a plateau, and again increases after an abrupt increase, as surface temperature increases. Since the ignition surface temperature is as high as $1912 \mathrm{~K}$, at which the combustion rate without $\mathrm{CO}$ flame is smaller than that with $\mathrm{CO}$ flame, not a decrease but an increase is predicted to occur abruptly

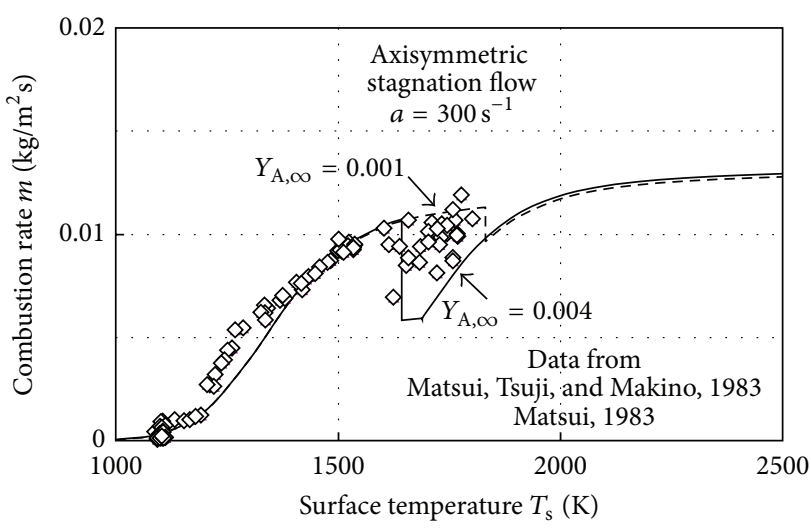

FIGURE 8: Combustion rate as a function of the surface temperature, with the $\mathrm{H}_{2} \mathrm{O}$ mass-fraction $Y_{\mathrm{A}, \infty}$ taken as a parameter. Data points are combustion rate measured in the axisymmetric stagnation airflow over a flat plate $[38,64]$; curves are calculated by use of the explicit combustion-rate expressions.

in the combustion rate, just after the appearance of the $\mathrm{CO}$ flame. It may be informative to note that this kind of an abrupt increase in the combustion rate has already been observed in the two-dimensional stagnation flow [28].

\section{Combustion in Humid Airflow}

Here, carbon combustion in humid airflow has been examined, focusing on promoting and suppressing effects of the water vapor in the airflow. From the practical point of view, the carbon combustion in airflow at high $\mathrm{H}_{2} \mathrm{O}$ concentrations is related to evaluating protection properties of rocket nozzles, made of carbonaceous materials, from erosive attacks of water vapor, contained in the working fluid for propulsion, as well as the coal/char combustion in such environments with an appreciable amount of water vapor.

6.1. Combustion in Relatively Dry Airflow. In order to have a clear image for the effect of water vapor on the combustion, let us first examine combustion behavior in relatively dry airflow or oxidizer flow. As shown in Figures 1(a), 1(b), 5(a), 7(a), and $7(b)$, the combustion rate increases with increasing surface temperature, up to the ignition surface temperature, which is quite sensitive to the water-vapor concentration in the gas phase. At the ignition surface temperature, there appears an abrupt change in the combustion rate, because appearance of the CO-flame alters the dominant surface reaction from the $\mathrm{C}-\mathrm{O}_{2}$ reaction to the $\mathrm{C}-\mathrm{CO}_{2}$ reaction. A further increase in the surface temperature raises the combustion rate and it reaches the diffusion-limited value. It should, however, be noted that this is the case that the $\mathrm{H}_{2} \mathrm{O}$ mass-fraction $Y_{\mathrm{A}, \infty}$ is strictly controlled. When its control is poor, the appearance of $\mathrm{CO}$ flame can necessarily cause a scatter in the combustion rate, as shown in Figure 8, being measured in the axisymmetric stagnation airflow over a flat plate $[38,64]$, due to the "unsteady" combustion that proceeds without CO flame at one time, while with CO flame at the other time. 


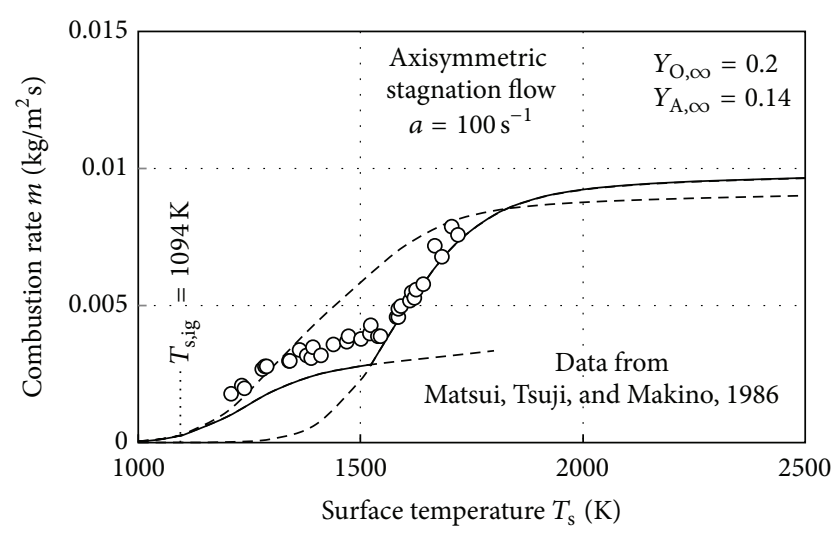

FIgURE 9: Combustion rate in humid airflow with the $\mathrm{H}_{2} \mathrm{O}$ massfraction $Y_{\mathrm{A}, \infty}=0.14$, as a function of the surface temperature $T_{\mathrm{s}}$. Data points are experimental [39] and curves are calculated by use of the explicit combustion-rate expressions.

Predicted results by use of the explicit combustion-rate expressions are also shown in Figure 8 as a function of the surface temperature, with the $\mathrm{H}_{2} \mathrm{O}$ mass-fraction $Y_{\mathrm{A}, \infty}$ taken as a parameter. In this prediction, use has been made of the surface kinetic parameters described in the previous works $[15,42,65]$ : for the $\mathrm{C}-\mathrm{O}_{2}$ reaction, $B_{\mathrm{s}, \mathrm{O}}=2.2 \times 10^{6} \mathrm{~m} / \mathrm{s}$ and $E_{\mathrm{s}, \mathrm{O}} / R=2.2 \times 10^{4} \mathrm{~K}\left(E_{\mathrm{s}, \mathrm{O}}=180 \mathrm{~kJ} / \mathrm{mol}\right)$; for the $\mathrm{C}-\mathrm{CO}_{2}$ reaction, $B_{\mathrm{s}, \mathrm{P}}=6.0 \times 10^{7} \mathrm{~m} / \mathrm{s}$ and $E_{\mathrm{s}, \mathrm{P}} / R=3.2 \times 10^{4} \mathrm{~K}\left(E_{\mathrm{s}, \mathrm{P}}=\right.$ $269 \mathrm{~kJ} / \mathrm{mol}$ ); for the $\mathrm{C}-\mathrm{H}_{2} \mathrm{O}$ reaction, $B_{\mathrm{s}, \mathrm{A}}=2.0 \times 10^{8} \mathrm{~m} / \mathrm{s}$ and $E_{\mathrm{s}, \mathrm{A}} / R=3.3 \times 10^{4} \mathrm{~K}\left(E_{\mathrm{s}, \mathrm{A}}=271 \mathrm{~kJ} / \mathrm{mol}\right)$. This is due to the fact that the type of artificial graphite of their test specimens is exactly the same as that in the previous works. It should be informative to note that $Y_{\mathrm{A}, \infty}=0.001$ in air corresponds to the dew point of $260 \mathrm{~K}\left(-13^{\circ} \mathrm{C}\right)$ and $Y_{\mathrm{A}, \infty}=0.004$ to the dew point of $275 \mathrm{~K}\left(+2^{\circ} \mathrm{C}\right)$, both of which are usual humidity that we encounter. As far as the trend and approximate magnitude are concerned, fair agreement is demonstrated. In this context, the scatter of the combustion rate [64], not included in the previous report [38] for $Y_{\mathrm{A}, \infty}=0.001$, can be attributed to the poor control of water-vapor concentration in the airflow.

6.2. Combustion Rate in Humid Airflow. A further increase in the $\mathrm{H}_{2} \mathrm{O}$ mass fraction can considerably change the combustion behavior [39]. The $\mathrm{H}_{2} \mathrm{O}$ mass-fraction $Y_{\mathrm{A}, \infty}$ is now increased to be 0.14 , the dew point of which is as high as $334 \mathrm{~K}\left(61^{\circ} \mathrm{C}\right)$. The airflow temperature is raised to $T_{\infty}=370 \mathrm{~K}$ for preventing condensation of water vapor, accordingly. Figure 9 shows the combustion rate in humid airflow of $a=100 \mathrm{~s}^{-1}$, as a function of the surface temperature $T_{s}$. The $\mathrm{O}_{2}$ mass fraction is reduced, because of the increased $\mathrm{H}_{2} \mathrm{O}$ concentration. It is seen that the combustion rate increases first gradually and then rapidly with increasing surface temperature. This trend is quite different from that in Figure 1(a). Therefore, we can say that the high $\mathrm{H}_{2} \mathrm{O}$ mass fraction is unfavorable for the enhancement of combustion rate, especially in the medium temperature range, because establishment of the $\mathrm{CO}$ flame is facilitated and hence suppresses the combustion rate. To the contrary, at high surface temperatures, the high $\mathrm{H}_{2} \mathrm{O}$ mass fraction is favorable because the water vapor can participate in the surface reaction as an additional oxidizer.

In order to elucidate causes for this trend, theoretical results are obtained by use of the formulation [56], to be described in the next section, with the surface $\mathrm{C}-\mathrm{H}_{2} \mathrm{O}$ and global gas-phase $\mathrm{H}_{2}-\mathrm{O}_{2}$ reactions taken into account, additionally. Not only results in the frozen and flame-detached modes but also that in the flame-attached mode are shown. It is seen that experimental results at temperatures lower than about $1550 \mathrm{~K}$ are in accordance with the theoretical result of the flame-attached mode, while those at temperatures higher than about $1600 \mathrm{~K}$ are in accordance with the result of the flame-detached mode. Since the ignition surface temperature predicted is as low as $1094 \mathrm{~K}$, no abrupt change in the combustion rate can be observed eventually, even though the $\mathrm{CO}$ flame is established. From these comparisons, we can deduce that because of the high $\mathrm{H}_{2} \mathrm{O}$ mass fraction in the airflow, the CO flame established at $1094 \mathrm{~K}$ adheres to the carbon surface, so that the combustion in the flame-attached mode prevails until $\mathrm{CO}$ ejection becomes strong enough to separate the CO flame from the surface. The difference between the combustion rate experimentally obtained and that in the flame-attached mode can be attributed to the finite rate of gas-phase reaction, because the airflow is neither fast in the velocity nor high in the temperature. As the surface temperature is further increased, the $\mathrm{CO}$ flame detaches, so that the combustion proceeds in the flame-detached mode. The rapid increase in the combustion rate at high temperatures can be attributed to the participation of the C$\mathrm{H}_{2} \mathrm{O}$ reaction.

6.3. Extended Formulation. Theoretical study [56] has already been conducted for the system with three surface reactions and two global gas-phase reactions, by extending the previous formulation. Although some of the assumptions introduced in Section 2 are not appropriate for systems with hydrogen species, use has been made of those as they are, for tractability, in order to capture fundamental aspects of the carbon combustion under prescribed situations.

By extending (26) to have contribution of the $\mathrm{C}-\mathrm{H}_{2} \mathrm{O}$ reaction, the combustion rate $\left(-f_{\mathrm{s}}\right)$ can be expressed as

$$
\delta\left(-f_{\mathrm{s}}\right)=A_{\mathrm{s}, \mathrm{O}} \widetilde{Y}_{\mathrm{O}, \mathrm{s}}+A_{\mathrm{s}, \mathrm{P}} \widetilde{Y}_{\mathrm{P}, \mathrm{s}}+A_{\mathrm{s}, \mathrm{A}} \widetilde{Y}_{\mathrm{A}, \mathrm{s}} .
$$

Again, use has been made of an assumption that all the surface reactions are the first order. The reduced surface Damköhler number $A_{\mathrm{s}, i}$, the surface Damköhler number $D a_{\mathrm{s}, i}$, and the stoichiometrically weighted mass fraction, relevant to the oxidizing species $i(=\mathrm{O}, \mathrm{P}, \mathrm{A})$ are also defined in the same manner as those in Section 2.

Although $Y_{i, s}$ must be determined through numerical calculations when the gas-phase kinetics is finite, they can be determined analytically for some limiting cases, as mentioned. One of them is the frozen mode, in which we have [28]

$$
\tilde{Y}_{i, \mathrm{~s}}=\frac{\tilde{Y}_{i, \infty}}{1+\beta+A_{\mathrm{s}, i}\left[\beta /\left(-f_{\mathrm{s}}\right)\right]} \quad(i=\mathrm{O}, \mathrm{P}, \mathrm{A}) .
$$


Another is the flame-attached mode in which $\mathrm{CO}$ and $\mathrm{H}_{2}$ produced at the surface reactions are immediately consumed, so that it looks that the CO flame adheres to the surface. In the same manner [28], we have

$$
\begin{gathered}
\tilde{Y}_{\mathrm{O}, \mathrm{s}}=\frac{\tilde{Y}_{\mathrm{O}, \infty}-2 \delta \beta}{1+\beta}, \quad \tilde{Y}_{\mathrm{P}, \mathrm{s}}=\frac{\tilde{Y}_{\mathrm{P}, \infty}+\delta \beta}{1+\beta}, \\
\tilde{Y}_{\mathrm{A}, \mathrm{s}}=\frac{\tilde{Y}_{\mathrm{A}, \infty}}{1+\beta} .
\end{gathered}
$$

The third is the flame-detached mode in which the gasphase reaction is infinitely fast and the CO flame locates in the gas phase. Although a coupling function

$$
\widetilde{Y}_{\mathrm{O}, \mathrm{s}}+\widetilde{Y}_{\mathrm{P}, \mathrm{s}}+\widetilde{Y}_{\mathrm{A}, \mathrm{s}}=\frac{\tilde{Y}_{\mathrm{O}, \infty}+\tilde{Y}_{\mathrm{P}, \infty}+\tilde{Y}_{\mathrm{A}, \infty}-\delta \beta}{1+\beta}
$$

can easily be obtained and we can also put $Y_{\mathrm{O}, \mathrm{s}}=0$ for this combustion situation, a separation of $Y_{\mathrm{A}, \mathrm{s}}$ from $Y_{\mathrm{P}, \mathrm{s}}$ is not straightforward. For this aim, an introduction of another species-enthalpy coupling function, say,

$$
\widetilde{T}+\widetilde{Y}_{\mathrm{O}}+(1-\widetilde{\mathrm{Q}}) \widetilde{Y}_{\mathrm{A}}
$$

is necessary, which yields

$$
\widetilde{Y}_{\mathrm{A}, \mathrm{s}}=\frac{1}{1-\widetilde{\mathrm{Q}}} \frac{\widetilde{T}_{\infty}-\widetilde{T}_{\mathrm{s}}+\widetilde{Y}_{\mathrm{O}, \infty}+(1-\widetilde{\mathrm{Q}}) \tilde{Y}_{\mathrm{A}, \infty}-\gamma}{1+\beta+A_{\mathrm{s}, \mathrm{A}}\left[\beta /\left(-f_{\mathrm{s}}\right)\right]} .
$$

Here, $\widetilde{Q}$ is the ratio of the heats of combustion of the $\mathrm{H}_{2}-\mathrm{O}_{2}$ and $\mathrm{CO}-\mathrm{O}_{2}$ reactions in the gas phase. For evaluating $\gamma$, use has been made of the temperature profile

$$
T=T_{\mathrm{s}}+\left(T_{\mathrm{f}}-T_{\mathrm{s}}\right)\left(\frac{\xi}{\xi_{\mathrm{f}}}\right)
$$

inside the flame, from which we have

$$
\begin{aligned}
\gamma= & \widetilde{T}_{\infty}-\widetilde{T}_{\mathrm{s}}+\widetilde{Y}_{\mathrm{O}, \infty}+(1-\widetilde{\mathrm{Q}}) \widetilde{Y}_{\mathrm{A}, \infty} \\
& +(1-\widetilde{\mathrm{Q}})\left(\widetilde{Y}_{\mathrm{A}, \mathrm{s}} \frac{1-\xi_{\mathrm{f}}}{\xi_{\mathrm{f}}}-\frac{\widetilde{Y}_{\mathrm{A}, \mathrm{f}}}{\xi_{\mathrm{f}}}\right),
\end{aligned}
$$

where use has been made of the coupling function in (98), evaluated at the flame. By further using $\xi_{\mathrm{f}}$ and $Y_{\mathrm{A}, \mathrm{f}}$, determined by use of other coupling functions $\widetilde{Y}_{\mathrm{O}}-\widetilde{Y}_{\mathrm{F}}-\widetilde{Y}_{\mathrm{H}}$ and $\widetilde{Y}_{\mathrm{H}}+\widetilde{Y}_{\mathrm{A}}$, respectively, we have from (99) as [56]

$$
\tilde{Y}_{\mathrm{A}, \mathrm{s}}=\frac{\tilde{Y}_{\mathrm{A}, \infty}}{1+\beta+A_{\mathrm{s}, \mathrm{A}}\left[\beta /\left(-f_{\mathrm{s}}\right)\right]\left(1-\tilde{Y}_{\mathrm{O}, \infty} / 2 \delta \beta\right)} .
$$

6.4. Approximate, Explicit Expressions for the Combustion Rate. By use of the approximate relation in (77), analytical expressions for the transfer number $\beta$ can be obtained as follows.
Frozen mode:

$$
\begin{aligned}
\beta \approx & \left(\frac{K A_{\mathrm{s}, \mathrm{O}}}{1+K A_{\mathrm{s}, \mathrm{O}}}\right)\left(\frac{2 W_{\mathrm{C}}}{W_{\mathrm{O}}} Y_{\mathrm{O}, \infty}\right)+\left(\frac{K A_{\mathrm{s}, \mathrm{P}}}{1+K A_{\mathrm{s}, \mathrm{P}}}\right) \\
& \times\left(\frac{W_{\mathrm{C}}}{W_{\mathrm{P}}} Y_{\mathrm{P}, \infty}\right)+\left(\frac{K A_{\mathrm{s}, \mathrm{A}}}{1+K A_{\mathrm{s}, \mathrm{A}}}\right)\left(\frac{W_{\mathrm{C}}}{W_{\mathrm{A}}} Y_{\mathrm{A}, \infty}\right) .
\end{aligned}
$$

Flame-detached mode:

$$
\begin{aligned}
\beta \approx \frac{1}{2}\left\{\frac{K A_{\mathrm{s}, \mathrm{P}}}{1+K A_{\mathrm{s}, \mathrm{P}}}\left(\frac{2 W_{\mathrm{C}}}{W_{\mathrm{O}}} Y_{\mathrm{O}, \infty}+\frac{W_{\mathrm{C}}}{W_{\mathrm{P}}} Y_{\mathrm{P}, \infty}\right)\right. \\
\left.+\frac{K A_{\mathrm{s}, \mathrm{A}}}{1+K A_{\mathrm{s}, \mathrm{A}}}\left(\frac{W_{\mathrm{C}}}{W_{\mathrm{O}}} Y_{\mathrm{O}, \infty}+\frac{W_{\mathrm{C}}}{W_{\mathrm{A}}} Y_{\mathrm{A}, \infty}\right)\right\} \\
+\frac{1}{2}\left[\left\{\frac{K A_{\mathrm{s}, \mathrm{P}}}{1+K A_{\mathrm{s}, \mathrm{P}}}\left(\frac{2 W_{\mathrm{C}}}{W_{\mathrm{O}}} Y_{\mathrm{O}, \infty}+\frac{W_{\mathrm{C}}}{W_{\mathrm{P}}} Y_{\mathrm{P}, \infty}\right)\right.\right. \\
\left.\quad-\frac{K A_{\mathrm{s}, \mathrm{A}}}{1+K A_{\mathrm{s}, \mathrm{A}}}\left(\frac{W_{\mathrm{C}}}{W_{\mathrm{O}}} Y_{\mathrm{O}, \infty}+\frac{W_{\mathrm{C}}}{W_{\mathrm{A}}} Y_{\mathrm{A}, \infty}\right)\right\}^{2} \\
+4 \frac{K A_{\mathrm{s}, \mathrm{P}}}{1+K A_{\mathrm{s}, \mathrm{P}}}\left(\frac{W_{\mathrm{C}}}{W_{\mathrm{O}}} Y_{\mathrm{O}, \infty}+\frac{W_{\mathrm{C}}}{W_{\mathrm{P}}} Y_{\mathrm{P}, \infty}\right) \\
\left.\times \frac{K A_{\mathrm{s}, \mathrm{A}}}{1+K A_{\mathrm{s}, \mathrm{A}}}\left(\frac{W_{\mathrm{C}}}{W_{\mathrm{A}}} Y_{\mathrm{A}, \infty}\right)\right]^{1 / 2}
\end{aligned}
$$

Flame-attached mode:

$$
\begin{gathered}
\beta \approx\left(\frac{1}{1+2 K A_{\mathrm{s}, \mathrm{O}}-K A_{\mathrm{s}, \mathrm{P}}}\right) \\
\times\left(K A_{\mathrm{s}, \mathrm{O}} \frac{2 W_{\mathrm{C}}}{W_{\mathrm{O}}} Y_{\mathrm{O}, \infty}+K A_{\mathrm{s}, \mathrm{P}} \frac{W_{\mathrm{C}}}{W_{\mathrm{P}}} Y_{\mathrm{P}, \infty}\right. \\
\left.+K A_{\mathrm{s}, \mathrm{A}} \frac{W_{\mathrm{C}}}{W_{\mathrm{A}}} Y_{\mathrm{A}, \infty}\right) .
\end{gathered}
$$

As the correction factor $K$ for the axisymmetric flow, we have (90) for the frozen and flame-attached modes and (91) for the flame-detached mode. As shown in Figure 9, experimental comparisons have already been conducted and a fair degree of agreement is demonstrated in general, suggesting appropriateness of the present analysis, including the choice of thermophysical properties used.

\section{Concluding Remarks}

In the present study, combustion of solid carbon has been examined through experimental comparisons. In order to have a clear understanding, the carbon combustion considered here is only that in the forward stagnation flowfield, being established by inserting a spherical specimen into a uniform flow or by impinging a uniform flow on a flat plate, the situation of which is closely related to those of ablative carbon heat shield and/or strongly convective carbon burning. In the formulation, an aerothermochemical analysis has been 
conducted, based on the chemically reacting boundary layer, with considering the surface $\mathrm{C}-\mathrm{O}_{2}$ and $\mathrm{C}-\mathrm{CO}_{2}$ reactions and the gas-phase $\mathrm{CO}-\mathrm{O}_{2}$ reaction. By virtue of the generalized species-enthalpy coupling functions, derived successfully, it has been demonstrated that there exists close coupling between the surface and gas-phase reactions that exerts influences on the combustion rate. Combustion response in the limiting situations has further been identified by using the generalized coupling functions.

After confirming the experimental fact that the combustion rate momentarily changes upon ignition, because establishment of the $\mathrm{CO}$ flame in the gas phase can change the dominant surface reaction from the faster $\mathrm{C}-\mathrm{O}_{2}$ reaction to the slower $\mathrm{C}-\mathrm{CO}_{2}$ reaction, focus has been put on the ignition of $\mathrm{CO}$ flame over the burning carbon in the prescribed flowfield and theoretical studies have been conducted by using the generalized coupling functions. The asymptotic expansion method has been used to derive the explicit ignition criterion, from which, in accordance with experimental results, it has been shown that ignition is facilitated with increasing surface temperature and oxidizer concentration, while suppressed with increasing velocity gradient. Then, an attempt has been made to estimate kinetic parameters for the gas-phase reactions, prior to the appearance of the CO flame. For this aim, use has been made of the ignition criterion theoretically obtained, by evaluating it at the ignition surfacetemperature experimentally determined.

Experimental comparisons have further been conducted and a fair degree of agreement has been demonstrated. In addition, an attempt has been made to obtain explicit combustion-rate expressions, presented by the transfer number in terms of the natural logarithmic term, just like that for droplet combustion. For the three limiting cases, explicit expressions have further been obtained by making an assumption of small combustion rate. It has even been found that before the establishment of $\mathrm{CO}$ flame the combustion rate can fairly be represented by the expression in the frozen mode, and that after the establishment of $\mathrm{CO}$ flame the combustion rate can be represented by the expression in the flame-attached and/or flame-detached modes. Since the present expressions are explicit and have fair accuracy, they are anticipated to make various contributions not only for qualitative and quantitative studies in facilitating understanding, but also for practical utility, such as designs of furnaces, combustors, ablative carbon heat-shields, and high-temperature structures with $\mathrm{C} / \mathrm{C}$-composites in various aerospace applications, as well as propulsion with using high-energy-density fuels.

Finally, carbon combustion in humid airflow has been studied, which can even be a basic research for erosive attacks of water vapor to $\mathrm{C} / \mathrm{C}$-composite in rocket nozzles. It has been found that the high $\mathrm{H}_{2} \mathrm{O}$ mass fraction is unfavorable for the enhancement of combustion rate, especially in the medium temperature range, because establishment of the $\mathrm{CO}$ flame is facilitated and hence suppresses the combustion rate. To the contrary, at high surface temperatures, the high $\mathrm{H}_{2} \mathrm{O}$ massfraction is favorable because the water vapor can participate in the surface reaction as an additional oxidizer. Theoretical results, obtained by additionally introducing the surface
C- $\mathrm{H}_{2} \mathrm{O}$ reaction and the global gas-phase $\mathrm{H}_{2}-\mathrm{O}_{2}$ reaction into the previous formulation, have also suggested the usefulness of the explicit expressions for the combustion rate, which can even be used in experimental comparisons for the $\mathrm{H}_{2} \mathrm{O}$ mass fraction of 0.14 .

Although essential feature of the carbon combustion has been captured to some extents, further progresses are strongly required for its firm understanding, because wide attention has been given to carbonaceous materials in various fields.

\section{Nomenclature}

A: Reduced surface Damköhler number

$a$ : Velocity gradient in the stagnation flowfield

B: Frequency factor

$b$ : Constant

C: Constant

$c_{p}:$ Specific heat capacity of gas

D: Diffusion coefficient

$D a$ : Damköhler number

$d$ : Diameter or constant

E: Activation energy

$F$ : Function defined in the ignition criterion

$f$ : Nondimensional streamfunction

$h_{D}$ : Mass-transfer coefficient

$j: \quad j=1$ and 0 designate axisymmetric and two-dimensional flows, respectively

$K$ : Factor

$k$ : Surface reactivity

$L: \quad$ Convective-diffusive operator

$\dot{m}$ : Dimensional mass burning (or combustion) rate

q: Heat of combustion per unit mass of $\mathrm{CO}$

$n$ : Exponent for the order of reaction

$R^{o}$ : Universal gas constant

$R$ : Curvature of surface or radius

$s$ : Boundary-layer variable along the surface

$T:$ Temperature

$T a$ : Activation temperature

$t$ : Time

$u$ : Velocity component along $x$

$V:$ Freestream velocity

$v$ : Velocity component along $y$

$W$ : Molecular weight

$w$ : Reaction rate

$x$ : Tangential distance along the surface

$Y:$ Mass fraction

$y$ : Normal distance from the surface.

\section{Greek Symbols}

$\alpha$ : Stoichiometric $\mathrm{CO}_{2}$-to-reactant mass ratio

$\beta$ : Conventional transfer number

$\gamma$ : Temperature gradient at the surface 
$\delta$ : Product $\mathrm{CO}_{2}$-to-carbon mass ratio

$\varepsilon$ : Measure of the thermal energy in the reaction zone relative to the activation energy

$\eta$ : Boundary-layer variable normal to the surface or perturbed concentration

$\Theta$ : Perturbed temperature in the outer region

$\theta$ : Perturbed temperature in the inner region

$\lambda$ : Parameter defined in the ignition analysis

$\mu$ : Viscosity

v: Stoichiometric coefficient

$\xi$ : Profile function

$\rho:$ Density

$\chi$ : Inner variable

$\psi$ : Streamfunction

$\omega$ : Reaction rate.

\section{Subscripts}

A: Water vapor or $\mathrm{C}-\mathrm{H}_{2} \mathrm{O}$ surface reaction

a: Critical value at flame attachment

C: Carbon

F: Carbon monoxide

f: $\quad$ Flame sheet

g: Gas phase

ig: Ignition

in: Inner region

max: Maximum value

mt: Mass transfer

$\mathrm{N}$ : Nitrogen

$\mathrm{O}$ : Oxygen or $\mathrm{C}-\mathrm{O}_{2}$ surface reaction

out: Outer region

P: Carbon dioxide or $\mathrm{C}-\mathrm{CO}_{2}$ surface reaction

R: Representative value

s: $\quad$ Surface

$\infty$ : Freestream or ambience.

\section{Superscripts}

$j: \quad j=1$ and 0 designate axisymmetric and two-dimensional flows, respectively

$n$ : Reaction order

$\sim$ : Nondimensional or stoichiometrically weighted

I: Differentiation with respect to $\eta$

*: Without water-vapor effect.

\section{References}

[1] H. R. Batchelder, R. M. Busche, and W. P. Armstrong, "Kinetics of coal gasification," Industrial and Engineering Chemistry, vol. 45, no. 9, pp. 1856-1878, 1953.

[2] M. Gerstein and K. P. Coffin, "Combustion of solid fuels," in Combustion Processes, B. Lewis, R. N. Pease, and H. S. Taylor, Eds., pp. 444-469, Princeton University Press, Princeton, NJ, USA, 1956.

[3] P. L. Walker Jr., F. Rusinko Jr., and L. G. Austin, "Gas reaction of carbon," in Advances in Catalysis and Related Subjects, D. D.
Eley, P. W. Selwood, and P. B. Weisz, Eds., vol. 11, pp. 133-221, Academic Press, New York, NY, USA, 1959.

[4] T. J. Clark, R. E. Woodley, and D. R. De Halas, "Gas-graphite systems," in Nuclear Graphite, R. E. Nightingale, Ed., pp. 387444, Academic Press, New York, NY, USA, 1962.

[5] L. N. Khitrin, The Physics of Combustion and Explosion, Israel Program for Scientific Translations, Jerusalem, Israel, 1962.

[6] M. F. Mulcahy and I. W. Smith, "Kinetics of combustion of pulverized fuel: a review of theory and experiment," Pure and Applied Chemistry, vol. 19, no. 1, pp. 81-108, 1969.

[7] H. G. Maahs, "Oxidation of carbon at high temperatures: reaction-rate control or transport control," NASA TN D-6310, 1971.

[8] D. E. Rosner, "High-temperature gas-solid reactions," Annual Review of Materials Science, vol. 2, pp. 573-606, 1972.

[9] R. H. Essenhigh, "Combustion and flame propagation in coal systems: a review," Symposium (International) on Combustion, vol. 16, no. 1, pp. 353-374, 1977.

[10] R. H. Essenhigh, "Fundamentals of coal combustion," in Chemistry of Coal Utilization, M. A. Elliott, Ed., pp. 1153-1312, WileyInterscience, New York, NY, USA, 1981.

[11] K. Annamalai and W. Ryan, "Interactive processes in gasification and combustion-II. Isolated carbon, coal and porous char particles," Progress in Energy and Combustion Science, vol. 19, no. 5, pp. 383-446, 1993.

[12] K. Annamalai, W. Ryan, and S. Dhanapalan, "Interactive processes in gasification and combustion-part III: coal/char particle arrays, streams and clouds," Progress in Energy and Combustion Science, vol. 20, no. 6, pp. 487-618, 1994.

[13] J. R. Arthur, "Reactions between carbon and oxygen," Transactions of the Faraday Society, vol. 47, pp. 164-178, 1951.

[14] H. Schlichting and K. Gestin, Plane Stagnation-Point Flow, Boundary Layer Theory, Springer, Berlin, Germany, 8th edition, 2000.

[15] A. Makino, "Mass transfer related to heterogeneous combustion of solid carbon in the forward stagnation region-part 1 : combustion rate and flame structure," in Mass Transfer in Chemical Engineering Processes, J. Markoš, Ed., pp. 251-282, InTech, Rijeka, Croatia, 2011, http://www.intechopen.com/articles/show/title/mass-transfer-related-to-heterogeneous-combustion-of-solid-carbon-in-the-forward-stagnation-region-1.

[16] A. Makino, "Mass transfer related to heterogeneous combustion of solid carbon in the forward stagnation region-part 2: combustion rate in special environments," in Mass Transfer in Chemical Engineering Processes, J. Markoš, Ed., pp. 281-306, InTech, Rijeka, Croatia, 2011, http://www.intechopen.com/articles/show/title/mass-transfer-related-to-heterogeneous-combustion-of-solid-carbon-in-the-forward-stagnation-region-2.

[17] H. Tsuji and K. Matsui, "An aerothermochemical analysis of combustion of carbon in the stagnation flow," Combustion and Flame, vol. 26, pp. 283-297, 1976.

[18] G. Adomeit, G. Mohiuddin, and N. Peters, "Boundary layer combustion of carbon," Symposium (International) on Combustion, vol. 16, no. 1, pp. 731-743, 1977.

[19] G. Adomeit, W. Hocks, and K. Henriksen, "Combustion of a carbon surface in a stagnation point flow field," Combustion and Flame, vol. 59, no. 3, pp. 273-288, 1985.

[20] K. Henriksen, W. Hocks, and G. Adomeit, "Combustion of a carbon surface in a stagnation point flow field-part II: ignition and quench phenomena," Combustion and Flame, vol. 71, no. 2, pp. 169-177, 1988. 
[21] K. Matsui and H. Tsuji, "An aerothermochemical analysis of solid carbon combustion in the stagnation flow accompanied by homogeneous CO oxidation," Combustion and Flame, vol. 70, no. 1, pp. 79-99, 1987.

[22] A. Makino and C. K. Law, "Quasi-steady and transient combustion of a carbon particle: theory and experimental comparisons," Symposium (International) on Combustion, vol. 21, no. 1, pp. 183-191, 1988.

[23] A. Makino, "A theoretical and experimental study of carbon combustion in stagnation flow," Combustion and Flame, vol. 81, no. 2, pp. 166-187, 1990.

[24] P. Chung, "Chemically reacting nonequilibrium boundary layers," in Advances in Heat Transfer, J. P. Hartnett and T. F. Irvine Jr., Eds., vol. 2, pp. 109-270, Academic Press, New York, NY, USA, 1965.

[25] C. K. Law, "On the stagnation-point ignition of a premixed combustible," International Journal of Heat and Mass Transfer, vol. 21, no. 11, pp. 1363-1368, 1978.

[26] D. B. Spalding, "Combustion of fuel particles," Fuel, vol. 30, no. 1, pp. 121-130, 1951.

[27] A. Makino, "An approximate explicit expression for the combustion rate of a small carbon particle," Combustion and Flame, vol. 90, no. 2, pp. 143-154, 1992.

[28] A. Makino, T. Namikiri, and N. Araki, "Combustion rate of graphite in a high stagnation flowfield and its expression as a function of the transfer number," Symposium (International) on Combustion, vol. 2, pp. 2949-2956, 1998.

[29] P. A. Libby and T. R. Blake, "Theoretical study of burning carbon particles," Combustion and Flame, vol. 36, pp. 139-169, 1979.

[30] S. K. Ubhayakar and F. A. Williams, "Burning and extinction of a laser-ignited carbon particle in quiescent mixtures of oxygen and nitrogen," Journal of the Electrochemical Society, vol. 123, no. 5, pp. 747-756, 1976.

[31] K. Henriksen, "Weak homogeneous burning in front of a carbon surface," Symposium (International) on Combustion, vol. 22, no. 1, pp. 47-57, 1989.

[32] A. Makino and C. K. Law, "Ignition and extinction of CO flame over a carbon rod," Combustion Science and Technology, vol. 73, no. 4-6, pp. 589-615, 1990.

[33] L. N. Khitrin and E. S. Golovina, "Interaction between graphite and various chemically active gases at high temperatures," in High Temperature Technology, pp. 485-496, Butterworths, London, UK, 1964.

[34] W. Visser and G. Adomeit, "Experimental investigation of the ignition and combustion of a graphite probe in cross flow," Symposium (International) on Combustion, vol. 20, no. 1, pp. 1845-1851, 1985.

[35] D. J. Harris and I. W. Smith, "Intrinsic reactivity of petroleum coke and brown coal char to carbon dioxide, steam and oxygen," Symposium (International) on Combustion, vol. 23, no. 1, pp. 1185-1190, 1991.

[36] J. B. Howard, G. C. Williams, and D. H. Fine, "Kinetics of carbon monoxide oxidation in postflame gases," Symposium (International) on Combustion, vol. 14, no. 1, pp. 975-986, 1973.

[37] K. Matsui, A. Kôyama, and K. Uehara, "Fluid-mechanical effects on the combustion rate of solid carbon," Combustion and Flame, vol. 25, pp. 57-66, 1975.

[38] K. Matsui, H. Tsuji, and A. Makino, "The effects of water vapor concentration on the rate of combustion of an artificial graphite in humid air flow," Combustion and Flame, vol. 50, pp. 107-118, 1983.
[39] K. Matsui, H. Tsuji, and A. Makino, "A further study of the effects of water vapor concentration on the rate of combustion of an artificial graphite in humid air flow," Combustion and Flame, vol. 63, no. 3, pp. 415-427, 1986.

[40] H. Schlichting and K. Gestin, Sphere, Boundary Layer Theory, Springer, Berlin, Germany, 8th edition, 2000.

[41] W. Visser, Verbrenung Einer Umströmten Graphitoberfläche [Ph.D. thesis], Institute für Allgemaine Mechanik, RWTH, Aachen, Germany, 1984.

[42] A. Makino, N. Araki, and Y. Mihara, "Combustion of artificial graphite in stagnation flow: estimation of global kinetic parameters from experimental results," Combustion and Flame, vol. 96, no. 3, pp. 261-274, 1994.

[43] J. Nagle and R. F. Strickland-Constable, "Oxidation of Carbon between 1000-2000 ${ }^{\circ} \mathrm{C}$," in Proceedings of the 5th Conference on Carbon, pp. 154-164, Pergamon, New York, NY, USA, 1962.

[44] R. T. Yang and M. Steinberg, "A diffusion cell method for studying heterogeneous kinetics in the chemical reaction/diffusion controlled region. Kinetics of $\mathrm{C}+\mathrm{CO}_{2} \rightarrow 2 \mathrm{CO}$ at $1200-$ $1600{ }^{\circ} \mathrm{C}$," Industrial and Engineering Chemistry Fundamentals, vol. 16, no. 2, pp. 235-242, 1977.

[45] A. Makino, I. Kato, M. Senba, H. Fujizaki, and N. Araki, "Flame structure and combustion rate of burning graphite in the stagnation flow," Symposium (International) on Combustion, vol. 26, no. 2, pp. 3067-3069, 1996.

[46] A. Makino, M. Senba, M. Shintomi, H. Fujizaki, and N. Araki, "Experimental determination of the spatial resolution of CARS in the combustion field-CARS thermometry applied to the combustion field of solid carbon in a stagnation flow," Nensho no Kagaku to Gijutsu (Combustion Science and Technology), vol. 5, no. 2, pp. 89-101, 1997 (Japanese).

[47] A. Liñán, "The asymptotic structure of counterflow diffusion flames for large activation energies," Acta Astronautica, vol. 1, no. 7-8, pp. 1007-1039, 1974.

[48] M. Matalon, "Complete burning and extinction of a carbon particle in an oxidizing atmosphere," Combustion Science and Technology, vol. 24, no. 3-4, pp. 115-127, 1980.

[49] M. Matalon, "Weak burning and gas-phase ignition about a carbon particle in an oxidizing atmosphere," Combustion Science and Technology, vol. 25, no. 1-2, pp. 43-48, 1981.

[50] M. Matalon, "The steady burning of a solid particle," SIAM Journal on Applied Mathematics, vol. 42, no. 4, pp. 787-803, 1982.

[51] H. Tsuji and I. Yamaoka, "The counterflow diffusion flame in the forward stagnation region of a porous cylinder," Symposium (International) on Combustion, vol. 11, no. 1, pp. 979-984, 1967.

[52] G. K. Sobolev, "High-temperature oxidation and burning of carbon monoxide," Symposium (International) on Combustion, vol. 7, no. 1, pp. 386-391, 1958.

[53] Z. Chukhanov, "The burning of carbon. 1. The sequence of processes in the combustion of air suspensions of solid fuels," Technical Physics of the USSR, vol. 5, pp. 41-58, 1938.

[54] Z. Chukhanov, "The Burning of Carbon-part II: oxidation," Technical Physics of the USSR, vol. 5, pp. 511-524, 1938.

[55] E. S. Golovina and G. P. Khaustovich, "The interaction of carbon with carbon dioxide and oxygen at temperatures up to $3000^{\circ} \mathrm{K}$," Symposium (International) on Combustion, vol. 8, no. 1, pp. 784792, 1991.

[56] A. Makino and N. Umehara, "Combustion rates of graphite rods in the forward stagnation field of the high-temperature, humid airflow," Proceedings of the Combustion Institute, vol. 31, no. 2, pp. 1873-1880, 2007. 
[57] K. Fischbeck, "Über das Reaktionsvermögen der Festen Stoffe," Zeitschrift für Elektrochemie und Angewandte Physikalische Chemie, vol. 39, no. 5, pp. 316-330, 1933.

[58] K. Fischbeck, L. Neundeubel, and F. Salzer, "Über das Reaktionsvermögen von Kristallarten," Zeitschrift für Elektrochemie und Angewandte Physikalische Chemie, vol. 40, pp. 517-522, 1934.

[59] C. M. Tu, H. Davis, and H. C. Hottel, "Combustion rate of carbon, combustion of spheres in flowing gas streams," Industrial and Engineering Chemistry, vol. 26, no. 7, pp. 749-757, 1934.

[60] D. A. Frank-Kamenetskii, Diffusion and Heat Transfer in Chemical Kinetics, edited by J. P. Appleton, Plenum, New York, NY, USA, 2nd edition, 1969.

[61] Y. Katto, An Outline of Heat Transfer, 1982.

[62] F. M. White, Heat and Mass Transfer, Addison-Wesley, Reading, Mass, USA, 1988.

[63] A. S. Parker and H. C. Hottel, "Combustion rate of carbon, study of gas-film structure by microsampling," Industrial and Engineering Chemistry, vol. 28, no. 11, pp. 1334-1341, 1936.

[64] K. Matsui, Private communications, 1983.

[65] A. Makino, H. Fujizaki, and N. Araki, "Combustion rate of burning graphite in a stagnation flow of water vapor," Combustion and Flame, vol. 113, no. 1-2, pp. 258-263, 1998. 

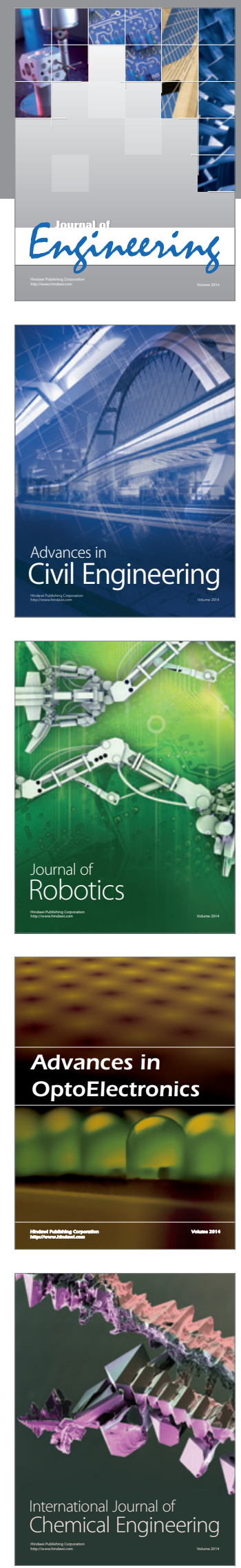

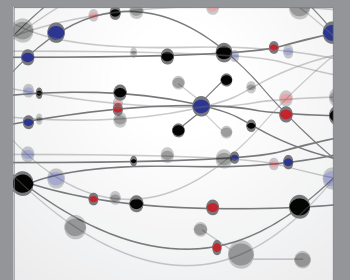

The Scientific World Journal
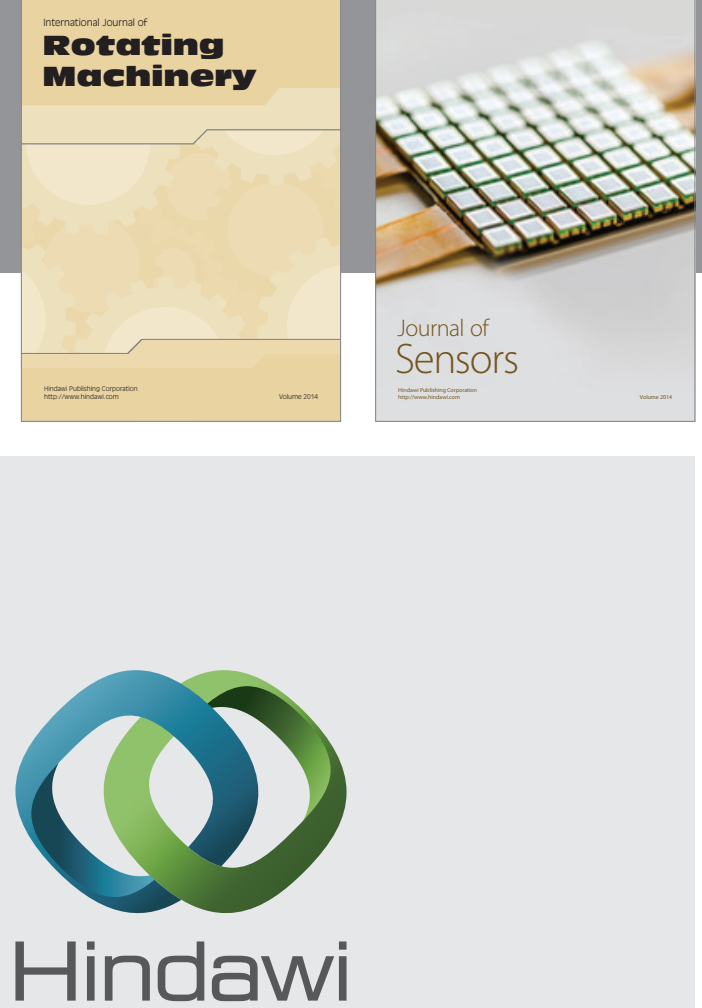

Submit your manuscripts at http://www.hindawi.com
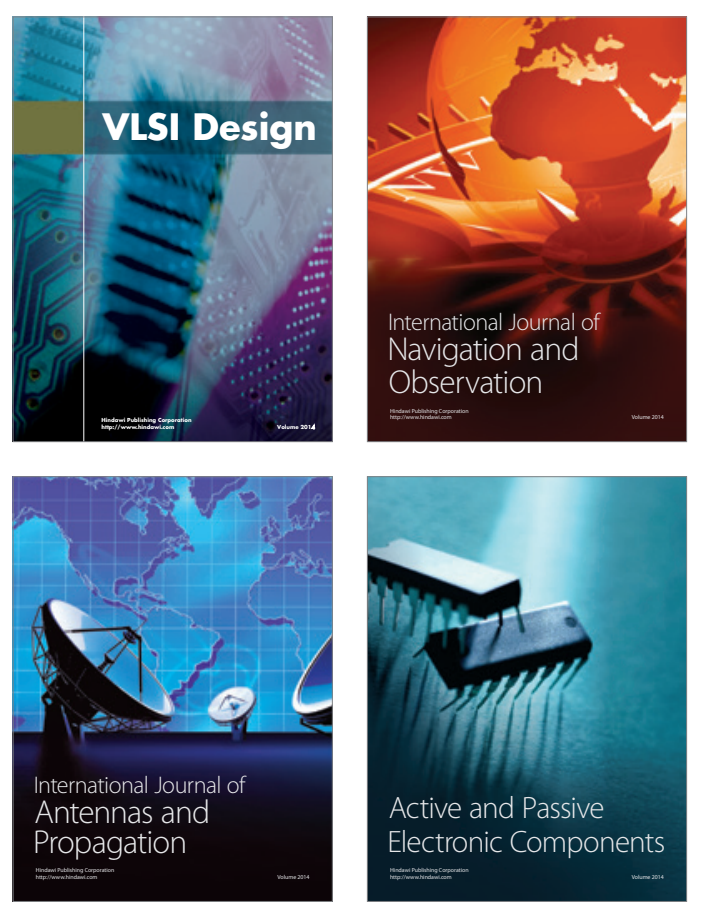
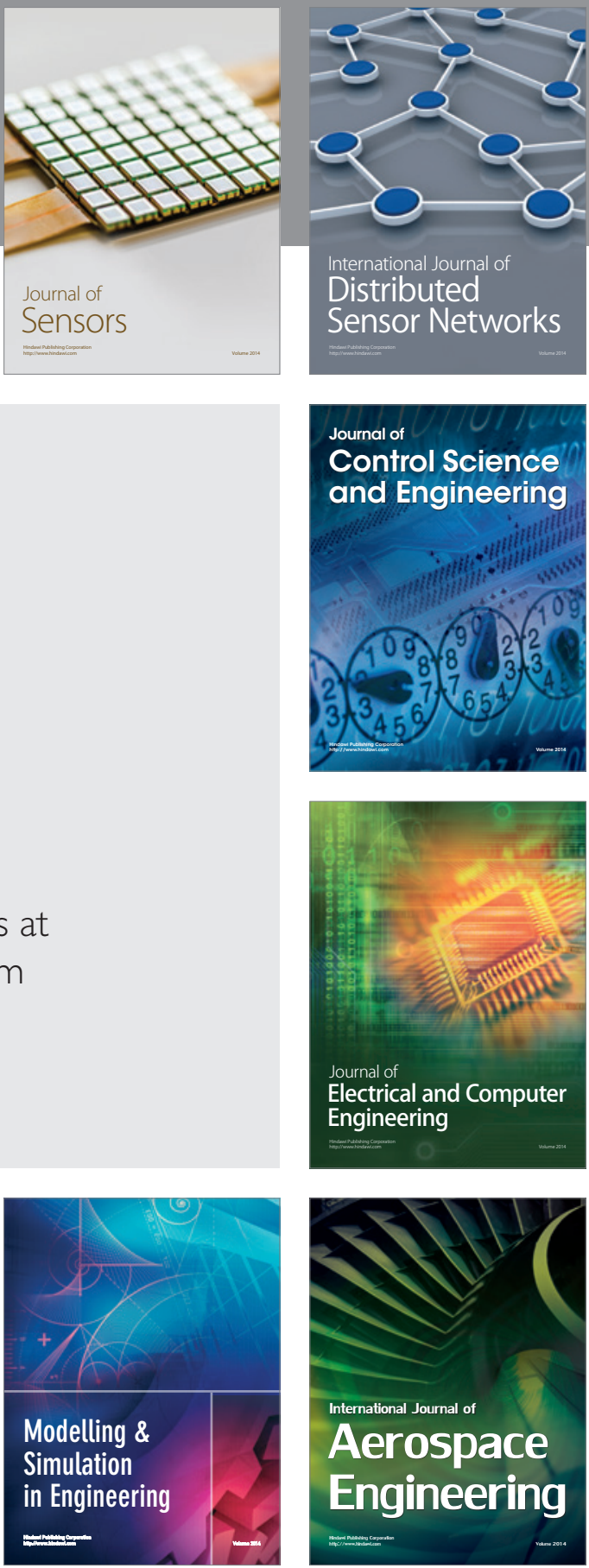

Journal of

Control Science

and Engineering
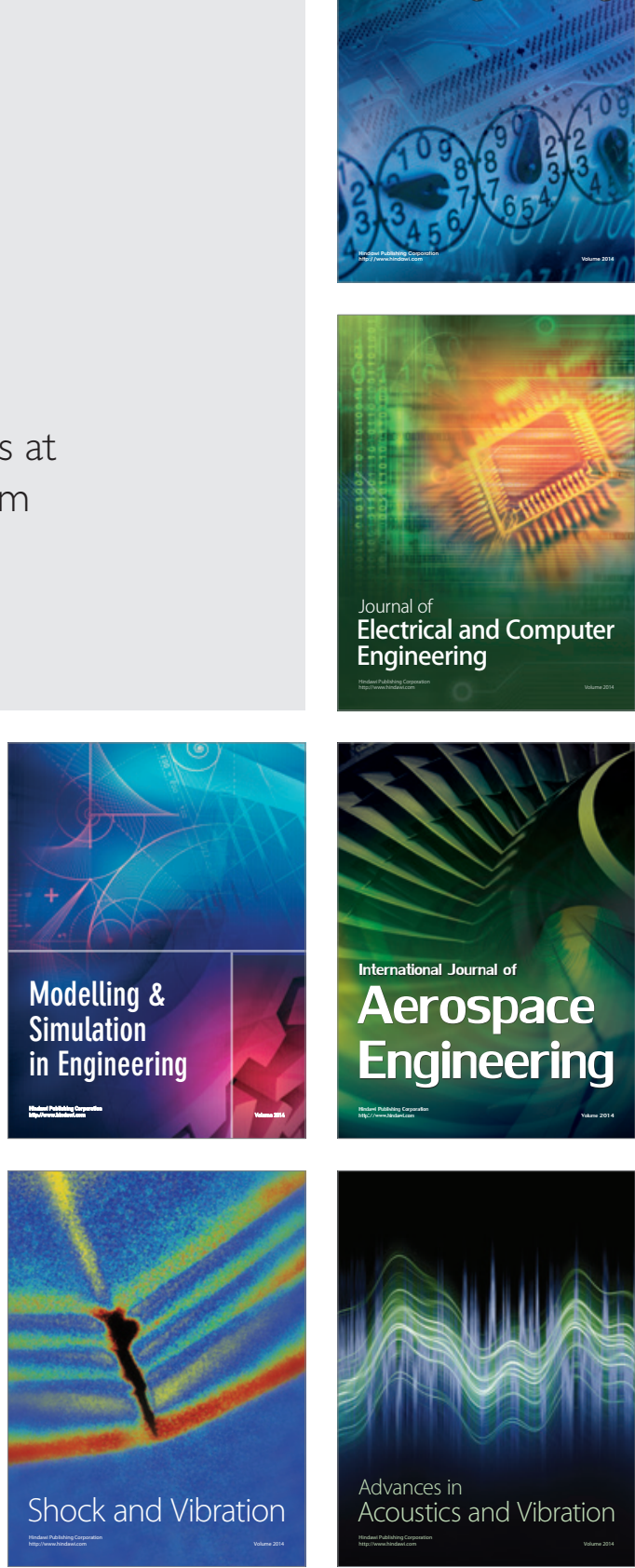